NCCN

Merkel Cell Carcinoma, Version 1.2018

\section{Clinical Practice Guidelines in Oncology}

Christopher K. Bichakjian, MD; Thomas Olencki, DO;

Sumaira Z. Aasi, MD; Murad Alam, MD, MBA, MSCl;

James S. Andersen, MD; Rachel Blitzblau, MD, PhD;

Glen M. Bowen, MD; Carlo M. Contreras, MD;

Gregory A. Daniels, MD, PhD; Roy Decker, MD, PhD;

Jeffrey M. Farma, MD; Kris Fisher, MD; Brian Gastman, MD;

Karthik Ghosh, MD; Roy C. Grekin, MD;

Kenneth Grossman, MD, PhD; Alan L. Ho, MD, PhD;

Karl D. Lewis, MD; Manisha Loss, MD;

Daniel D. Lydiatt, DDS, MD; Jane Messina, MD;
Kishwer S. Nehal, MD; Paul Nghiem, MD, PhD;

Igor Puzanov, MD, MSCl; Chrysalyne D. Schmults, MD, MS;

Ashok R. Shaha, MD; Valencia Thomas, MD;

Yaohui G. Xu, MD, PhD; John A. Zic, MD;

Karin G. Hoffmann, RN, CCM; and Anita M. Engh, PhD

\section{Overview}

Merkel cell carcinoma (MCC) is a cutaneous neuroendocrine neoplasia formerly called trabecular carcinoma. Although rare, with approximately 2,488 cases per year diagnosed in the United States, ${ }^{1} \mathrm{MCC}$ is one of the most aggressive skin cancers, and its incidence is dramatically increasing. ${ }^{2-10}$ Population studies have found that the incidence of MCC started to rise in the early 1990s, and is increasing 5\%-10\% per year, about 2.5-fold over 10 years, 3 -fold over 15

\title{
Abstract
}

This selection from the NCCN Guidelines for Merkel Cell Carcinoma (MCC) focuses on areas impacted by recently emerging data, including sections describing MCC risk factors, diagnosis, workup, follow-up, and management of advanced disease with radiation and systemic therapy. Included in these sections are discussion of the new recommendations for use of Merkel cell polyomavirus as a biomarker and new recommendations for use of checkpoint immunotherapies to treat metastatic or unresectable disease. The next update of the complete version of the NCCN Guidelines for MCC will include more detailed information about elements of pathology and addresses additional aspects of management of $\mathrm{MCC}$, including surgical management of the primary tumor and draining nodal basin, radiation therapy as primary treatment, and management of recurrence.

J Natl Compr Canc Netw 2018;16(6):742-774 doi: 10.6004/jnccn.2018.0055

\section{NCCN Categories of Evidence and Consensus}

Category 1: Based upon high-level evidence, there is uniform NCCN consensus that the intervention is appropriate.

Category 2A: Based upon lower-level evidence, there is uniform NCCN consensus that the intervention is appropriate.

Category 2B: Based upon lower-level evidence, there is NCCN consensus that the intervention is appropriate.

Category 3: Based upon any level of evidence, there is major NCCN disagreement that the intervention is appropriate.

All recommendations are category $2 \mathrm{~A}$ unless otherwise noted.

Clinical trials: NCCN believes that the best management for any cancer patient is in a clinical trial. Participation in clinical trials is especially encouraged.

\section{Please Note}

The NCCN Clinical Practice Guidelines in Oncology (NCCN Guidelines ${ }^{\circledR}$ ) are a statement of consensus of the authors regarding their views of currently accepted approaches to treatment. Any clinician seeking to apply or consult the NCCN Guidelines ${ }^{\circledR}$ is expected to use independent medical judgment in the context of individual clinical circumstances to determine any patient's care or treatment. The National Comprehensive Cancer Network $^{\circledR}\left(\mathrm{NCCN}^{\circledR}\right)$ makes no representation or warranties of any kind regarding their content, use, or application and disclaims any responsibility for their applications or use in any way. The full NCCN Guidelines for Merkel Cell Carcinoma are not printed in this issue of JNCCN but can be accessed online at NCCN.org.

(C) National Comprehensive Cancer Network, Inc. 2018, All rights reserved. The NCCN Guidelines and the illustrations herein may not be reproduced in any form without the express written permission of NCCN.

\section{Disclosures for the NCCN Merkel Cell Carcinoma Panel}

At the beginning of each NCCN Guidelines panel meeting, panel members review all potential conflicts of interest. NCCN, in keeping with its commitment to public transparency, publishes these disclosures for panel members, staff, and NCCN itself.

Individual disclosures for the NCCN Merkel Cell Carcinoma Panel members can be found on page 774. (The most recent version of these guidelines and accompanying disclosures are available on the NCCN Web site at NCCN.org.)

These guidelines are also available on the Internet. For the latest update, visit NCCN.org. 


\section{Journal of the National Comprehensive Cancer Network}

years, and 5.4-fold over 18 years. ${ }^{2,4-6,11}$ MCC tumors are frequently misdiagnosed ${ }^{12-16}$ so part of the apparent increase in incidence may be due to the discovery of biomarkers that improve detection of the disease. ${ }^{17}$ MCC can grow rapidly and metastasize early, ${ }^{18}$ with $63 \%$ of primary lesions having grown rapidly in the 3 months prior to diagnosis, ${ }^{14} 26 \%-36 \%$ presenting with lymph node involvement, and $6 \%-16 \%$ presenting with distant metastatic disease according to US studies. $2,17,19-22$ tients with MCC develop lymph node metastases and nearly one third develop distant metastases. ${ }^{23-26}$ Smaller but more recent studies have reported similar or higher rates of regional and distant metastases. ${ }^{27-29}$ Several large studies $(n>100)$ document the development of recurrence in $25 \%$ to $50 \%$ of all cases of MCC. 5,15,18,25,26,30 MCC has a high mortality rate exceeding melanoma. Large meta-analyses have shown that at least half of pa-

The 5-year relative or MCC-specific survival rates range from $41 \%$ to $77 \%, 3,5-7,17,19,22,30,31$ and depend on stage at presentation. $^{5-7,15,17,19-22,26,30,32-34}$

\section{Risk Factors for MCC}

Sun exposure is believed to be a major risk factor for MCC, based on increased incidence in geographical areas with higher UV indices, ${ }^{17,35,36}$ increased incidence in patients with extensive prior UVA photochemotherapy, ${ }^{37}$ the tendency to occur on the areas of the skin that are exposed to the sun $(81 \%)$, such as the head and neck $(29 \%-48 \%$ of all primary MC Cs), $15,17,19,20,25,26,30,33,35,38,39$ and the frequency of MCCs comingled or adjacent to other skin lesions caused by UV exposure. ${ }^{13,16,40-42}$ Recent genetic analyses have found much higher mutational burden in Merkel cell polyomavirus (MCPyV)-negative tumors and that only

Text cont. on page 754

\section{NCCN Merkel Cell Carcinoma Panel Members}

*Christopher K. Bichakjian, MD/Chairø

University of Michigan Rogel Cancer Center

Thomas Olencki, DO/Vice Chairt

The Ohio State University Comprehensive Cancer Center -

James Cancer Hospital and Solove Research Institute

Sumaira Z. Aasi, MDw

Stanford Cancer Institute

Murad Alam, MD, MBA, MSCIøףל

Robert H. Lurie Comprehensive Cancer Center of

Northwestern University

James S. Andersen, MDף

City of Hope Comprehensive Cancer Center

Rachel Blitzblau, MD, PhD§

Duke Cancer Center

Glen M. Bowen, MDш

Huntsman Cancer Institute at the University of Utah

Carlo M. Contreras, MDף

University of Alabama at Birmingham

Comprehensive Cancer Center

Gregory A. Daniels, MD, PhD $† \neq P$

UC San Diego Moores Cancer Center

Roy Decker, MD, PhD§

Yale Cancer Center/Smilow Cancer Hospital

Jeffrey M. Farma, MDף

Fox Chase Cancer Center

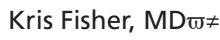

St. Jude Children's Research Hospital/

The University of Tennessee Health Science Center

Brian Gastman, MDŸ

Case Comprehensive Cancer Center/

University Hospitals Seidman Cancer Center and

Cleveland Clinic Taussig Cancer Institute

Karthik Ghosh, MDP

Mayo Clinic Cancer Center

Roy C. Grekin, MDшף

UCSF Helen Diller Family Comprehensive Cancer Center

Kenneth Grossman, MD, PhD†

Huntsman Cancer Institute at the University of Utah
Alan L. Ho, MD, PhD十

Memorial Sloan Kettering Cancer Center

Karl D. Lewis, MD†

University of Colorado Cancer Center

Manisha Loss, MDw

The Sidney Kimmel Comprehensive Cancer Center at

Johns Hopkins

Daniel D. Lydiatt, DDS, MDף

Fred \& Pamela Buffett Cancer Center

Jane Messina, MD\#

Moffitt Cancer Center

Memorial Sloan Kettering Cancer Center

Paul Nghiem, MD, PhDw

University of Washington/Seattle Cancer Care Alliance

Igor Puzanov, MD, MSCl‡

Roswell Park Comprehensive Cancer Center

Chrysalyne D. Schmults, MD, MSøி

Dana-Farber/Brigham and Women's Cancer Center

Ashok R. Shaha, MDףל

Memorial Sloan Kettering Cancer Center

Valencia Thomas, MDø

The University of Texas MD Anderson Cancer Center

Yaohui G. Xu, MD, PhDø

University of Wisconsin Carbone Cancer Center

John A. Zic, MDø

Vanderbilt-Ingram Cancer Center

NCCN Staff: Karin G. Hoffmann, RN, CCM, and Anita M. Engh, PhD

KEY:

*Discussion Section Writing Committee

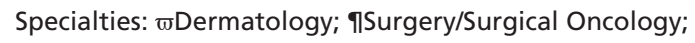
לOtolaryngology; $\neq$ Pathology/Dermatopathology; †Medical Oncology; PInternal Medicine; §Radiotherapy/Radiation Oncology; ŸReconstructive Surgery; ‡Hematology/Hematology Oncology
Kishwer S. Nehal, MDøி 
CLINICAL

PRESENTATION
PRELIMINARY WORKUP
DIAGNOSIS

\section{ADDITIONAL}

WORKUPa
CLINICAL FINDINGS

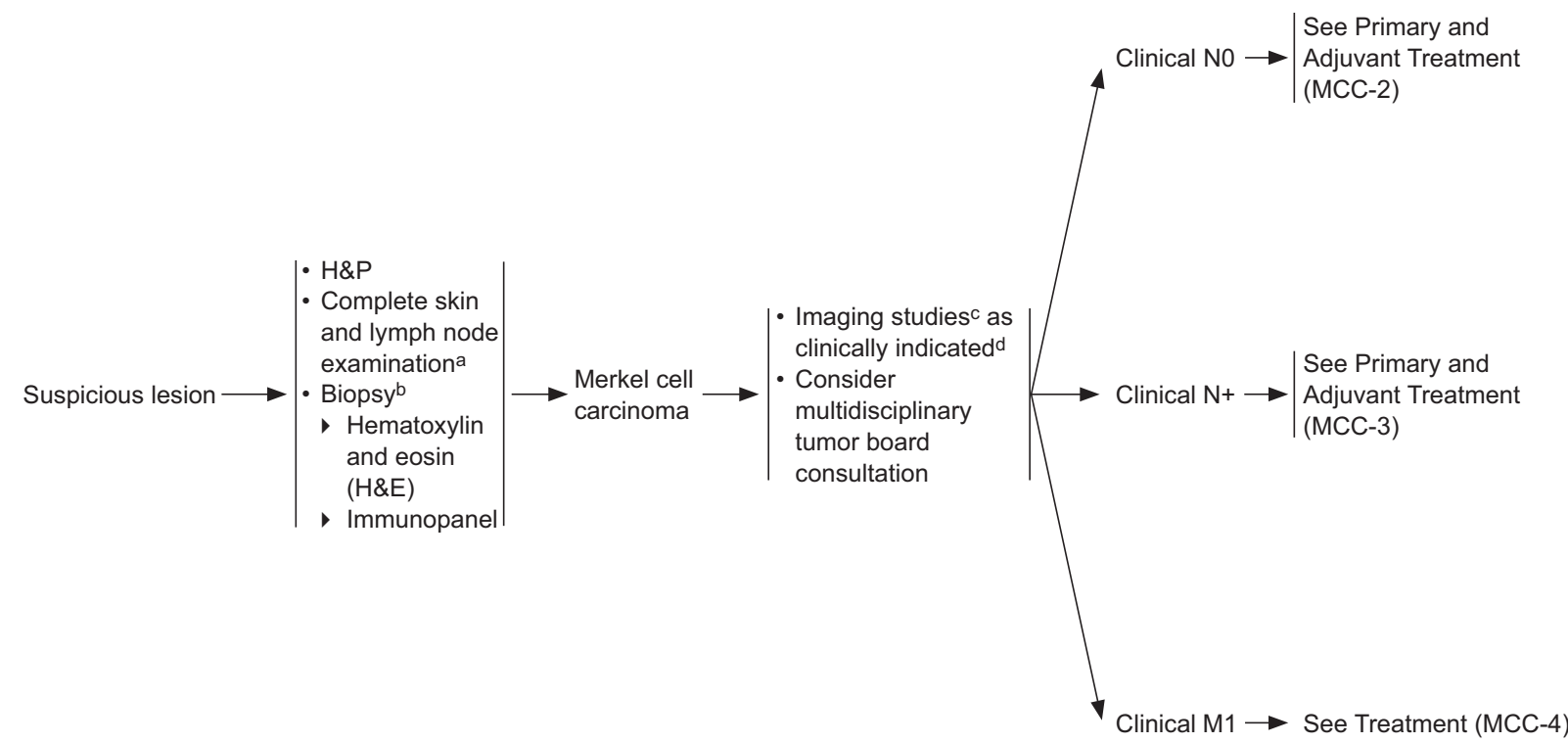

aQuantitation of MCPyV oncoprotein antibodies may be considered as part of initial workup; sero-negative patients may have a higher risk of recurrence; in sero-positive patients, a rising titer may be an early indicator of recurrence.

bSee Principles of Pathology (MCC-A).

CBrain MRI with contrast and neck/chest/abdomen/pelvis CT with contrast or whole body FDG PET/CT may be useful to identify and quantify regional and distant metastases. Some studies indicate that whole body FDG PET/CT may be preferred in some clinical circumstances. If whole body FDG PET/CT is not available, CT or MRI with contrast may be used. Imaging may also be useful to evaluate for the possibility of a skin metastasis from a noncutaneous primary neuroendocrine carcinoma (eg, small cell lung cancer), especially in cases where CK-20 is negative.

dImaging is encouraged whenever metastatic or unresectable disease is suspected based on H\&P findings. The most reliable staging tool to identify subclinical nodal disease is sentinel lymph node biopsy (SLNB). 


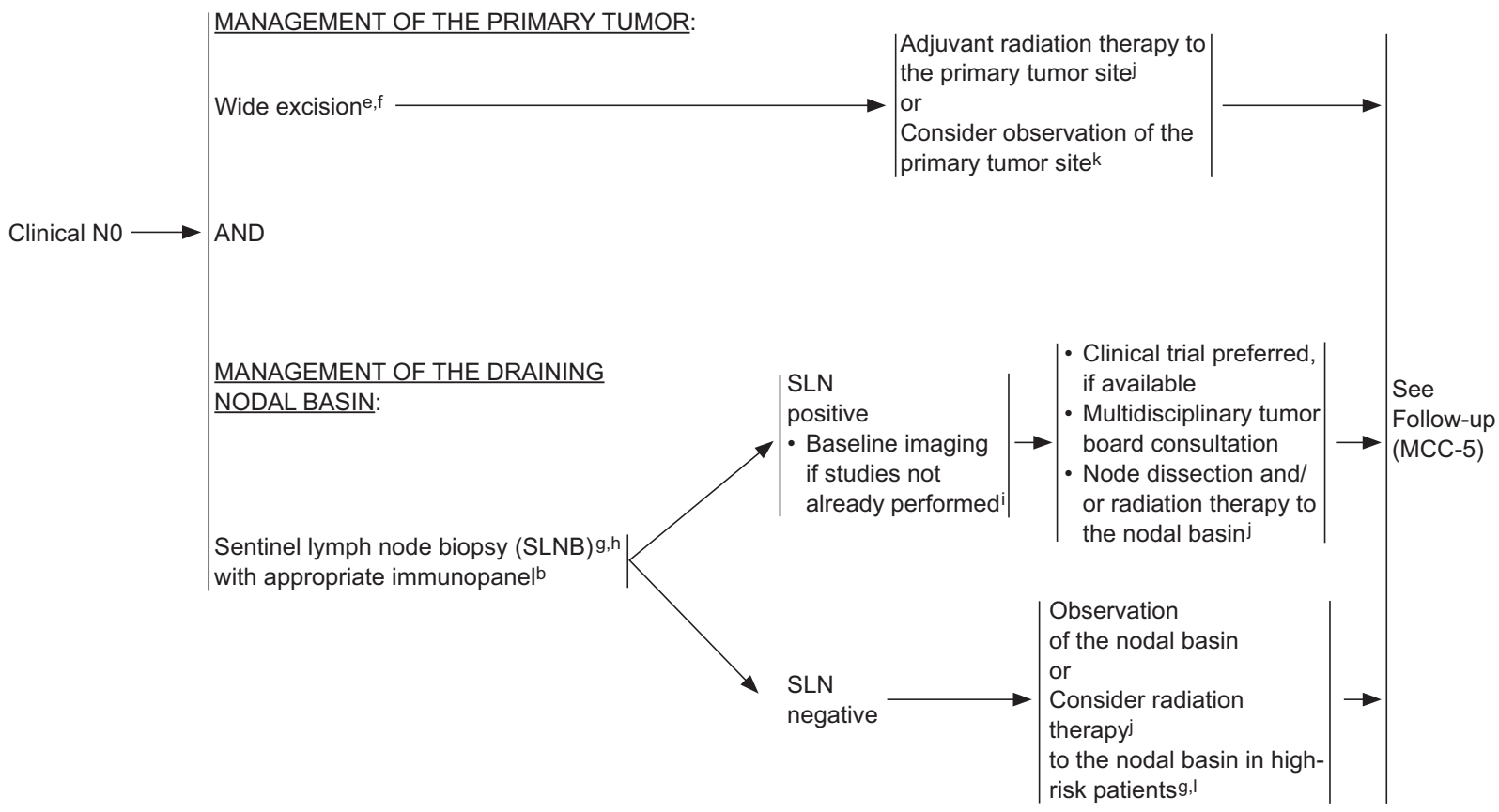

bSee Principles of Pathology (MCC-A).

esee Principles of Excision (MCC-C). In selected cases in which complete surgical excision is not possible, surgery is refused by the patient, or surgery would result in significant morbidity, radiation monotherapy may be considered (See Principles of Radiation Therapy [MCC-B]).

fSurgical margins should be balanced with morbidity of surgery. If appropriate, avoid undue delay in proceeding to RT (See Principles of Excision MCC-C).

gIn the head and neck region, risk of false-negative SLNBs is higher due to aberrant lymph node drainage and frequent presence of multiple SLN basins. If SLNB is not performed or is unsuccessful, consider irradiating nodal beds for subclinical disease (See Principles of Radiation Therapy MCC-B).

hSLNB is an important staging tool for regional control, but the impact of SLNB on overall survival is unclear.

iBrain MRI with contrast and neck/chest/abdomen/pelvis CT with contrast or whole body FDG PET/CT may be useful to identify and quantify regional and distant metastases. Some studies indicate that whole body FDG PET/CT may be preferred in some clinical circumstances. If whole body FDG PET/CT is not available, CT or MRI with contrast may be used.

isee Principles of Radiation Therapy (MCC-B).

${ }^{k}$ Consider observation of the primary site in cases where the primary tumor is small $(\mathrm{eg},<1 \mathrm{~cm})$ and widely excised with no other adverse risk factors such as LVI (lymphovascular invasion) or immunosuppression.

IConsider RT when there is a potential for anatomic [eg, previous history of surgery including WLE (wide local excision)], operator, or histologic failure (eg, failure to perform appropriate immunohistochemistry on SLNs) that may lead to a false-negative SLNB. Consider RT in cases of profound immunosuppression. 


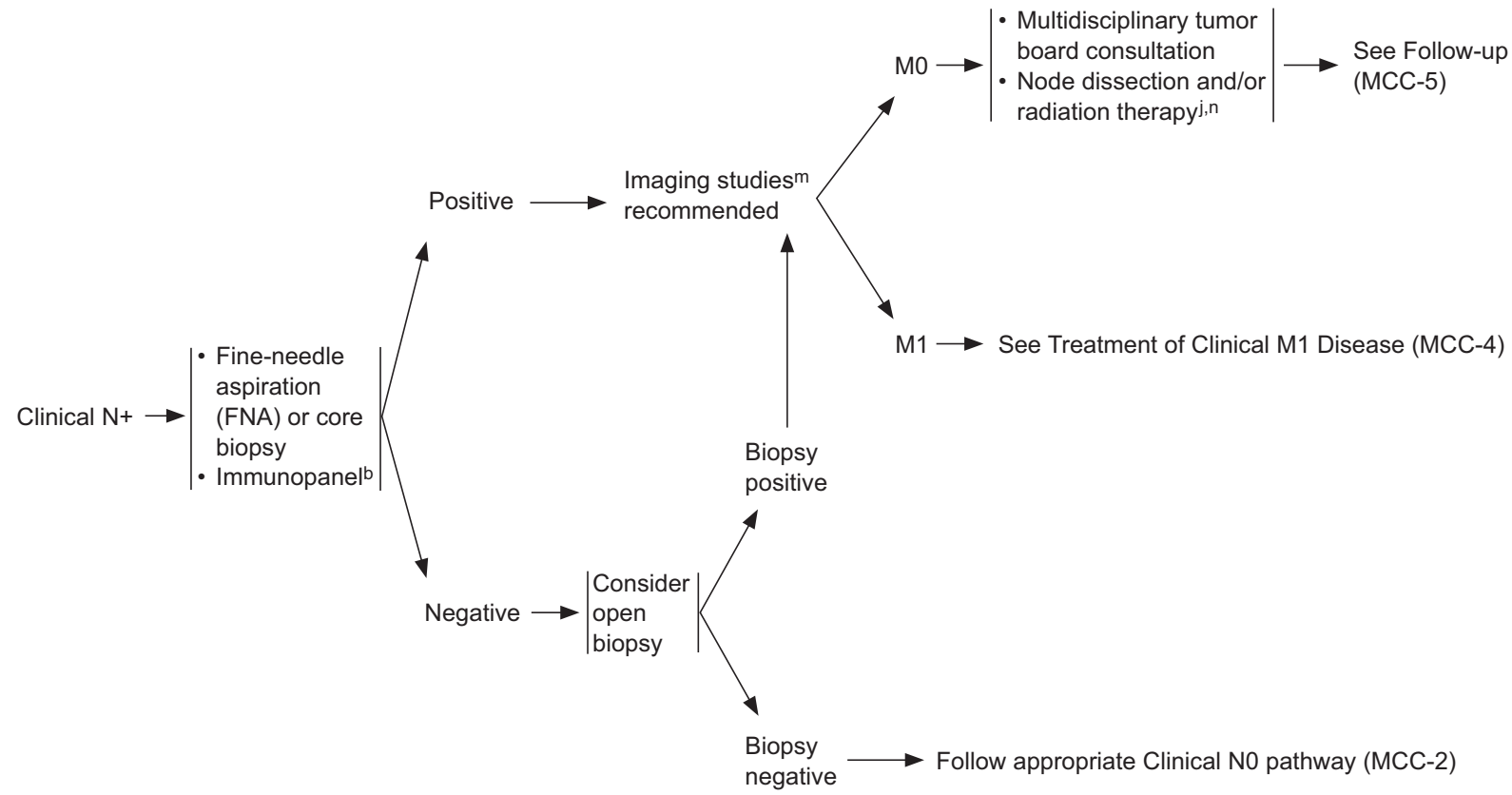

bSee Principles of Pathology (MCC-A).

jSee Principles of Radiation Therapy (MCC-B).

mBrain MRI with contrast and neck/chest/abdomen/pelvis CT with contrast or whole body FDG PET/CT to evaluate extent of lymph node and/or visceral organ involvement. Some studies indicate that whole body FDG PET/CT may be preferred in some clinical circumstances. If whole body FDG PET/CT is not available, CT or MRI with contrast may be used.

${ }^{n}$ Adjuvant chemotherapy may be considered in select clinical circumstances; however, available retrospective studies do not suggest survival benefit for adjuvant chemotherapy. (See Principles of Systemic Therapy [MCC-D]). 


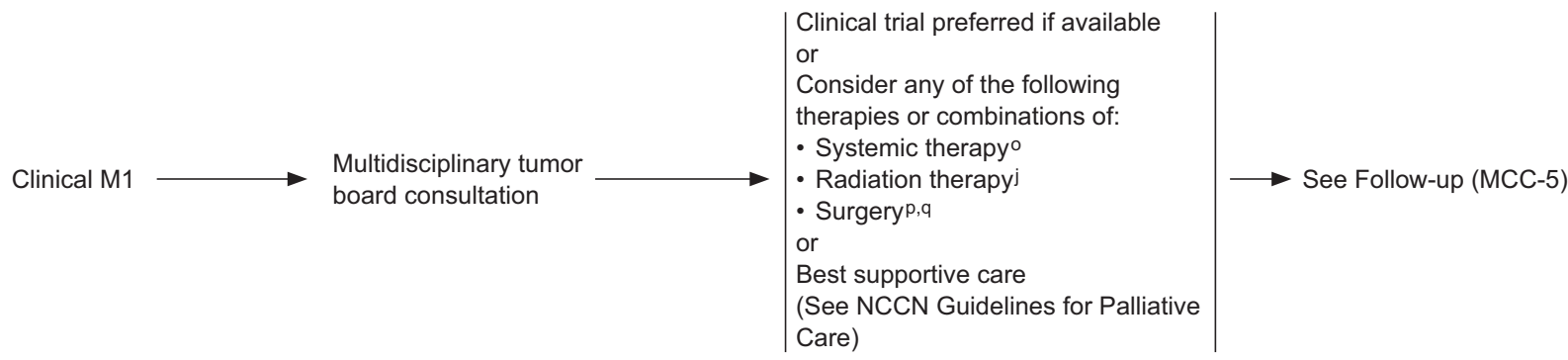


National

Comprehensive

NCCN Cancer

Network $^{\circledR}$

Follow-up visits:

- Physical exam including complete skin and complete lymph node exam

- Every 3-6 mo for 3 years

- Every 6-12 mo thereafter

- Imaging studies as clinically indicatedi

- Consider routine imaging for high-risk patients

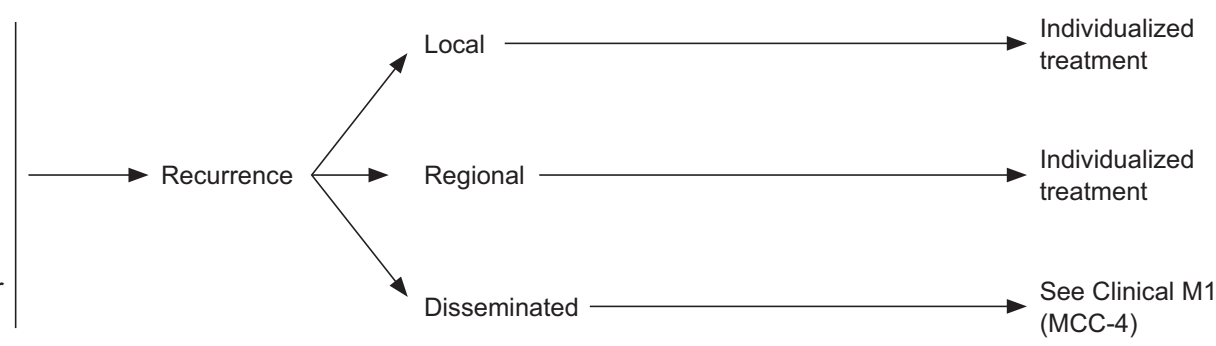

aQuantitation of MCPyV oncoprotein antibodies may be considered as part of initial workup; sero-negative patients may have a higher risk of recurrence; in sero-positive patients, a rising titer may be an early indicator of recurrence.

iBrain MRI with contrast and neck/chest/abdomen/pelvis CT with contrast or whole body FDG PET/CT may be useful to identify and quantify regional and distant metastases. Some studies indicate that whole body FDG PET/CT may be preferred in some clinical circumstances. If whole body FDG PET/CT is not available, CT or MRI with contrast may be used.

rAs immunosuppressed patients are at high risk for recurrence, more frequent follow-up may be indicated. Immunosuppressive treatments should be minimized as clinically feasible.

MCC-5

Clinical trials: NCCN believes that the best management of any patient with cancer is in a clinical trial. Participation in clinical trials is especially encouraged. All recommendations are category $2 \mathrm{~A}$ unless otherwise indicated.

(C) JNCCN_Journal of the National Comprehensive Cancer Network | Volume 16 Number 6 | June 2018 


\section{PRINCIPLES OF PATHOLOGY}

- Pathologist should be experienced in distinguishing MCC from cutaneous simulants and metastatic tumors.

- Synoptic reporting is preferred.

- Minimal elements to be reported include tumor size $(\mathrm{cm})$, peripheral and deep margin status, lymphovascular invasion, and extracutaneous extension (ie, bone, muscle, fascia, cartilage).

- Strongly encourage reporting of these additional clinically relevant factors (compatible with the American Joint Committee on Cancer [AJCC] and the College Of American Pathologists [CAP] recommendations):

- Depth (Breslow, in mm)

- Mitotic index (\#/mm² preferred, \#/HPF [High-power fields], or MIB-1 index)

- Tumor-infiltrating lymphocytes (not identified, brisk, non-brisk)

- Tumor growth pattern (nodular or infiltrative)

- Presence of a second malignancy within the pathologic specimen itself (ie, concurrent squamous cell carcinoma [SCC])

- An appropriate immunopanel should preferably include CK20 and thyroid transcription factor-1 (TTF-1). Immunohistochemistry for CK20 and most low-molecular-weight cytokeratin markers is typically positive with a paranuclear "dot-like" pattern. CK7 and TTF-1 (positive in $>80 \%$ of small cell lung cancers) are typically negative.

- For equivocal lesions, consider additional immunostaining with neuroendocrine markers such as chromogranin, synaptophysin, CD56, neuron-specific enolase (NSE), and neurofilament.

- SLNB evaluation should preferably include an appropriate immunopanel (ie, CK20 and pancytokeratins [AE1/AE3]) based on the immunostaining pattern of the primary tumor, particularly if H\&E sections are negative, as well as tumor burden (\% of node), tumor location (eg, subcapsular sinus, parenchyma), and the presence/absence of extracapsular extension. 


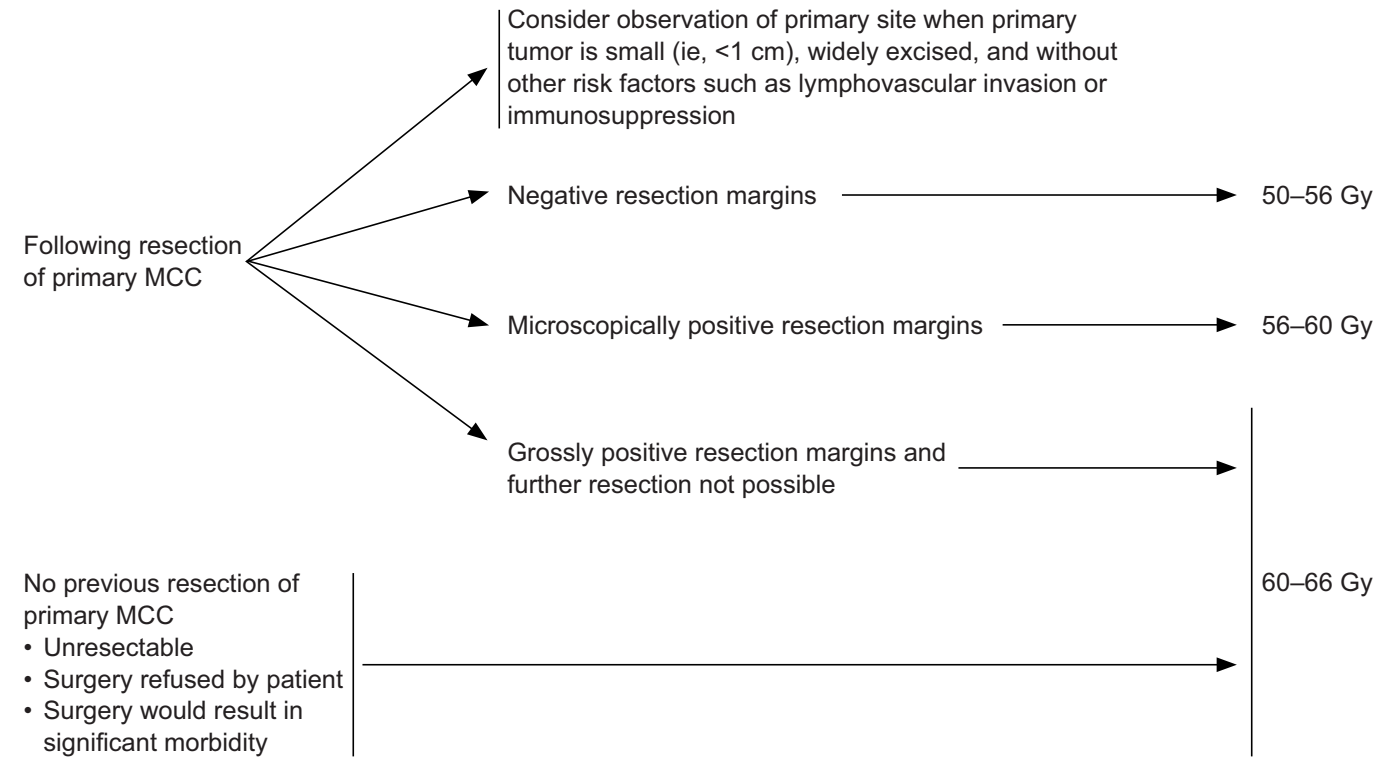




\section{PRINCIPLES OF RADIATION THERAPY}

DRAINING NODAL BASIN

DOSE RECOMMENDATIONS

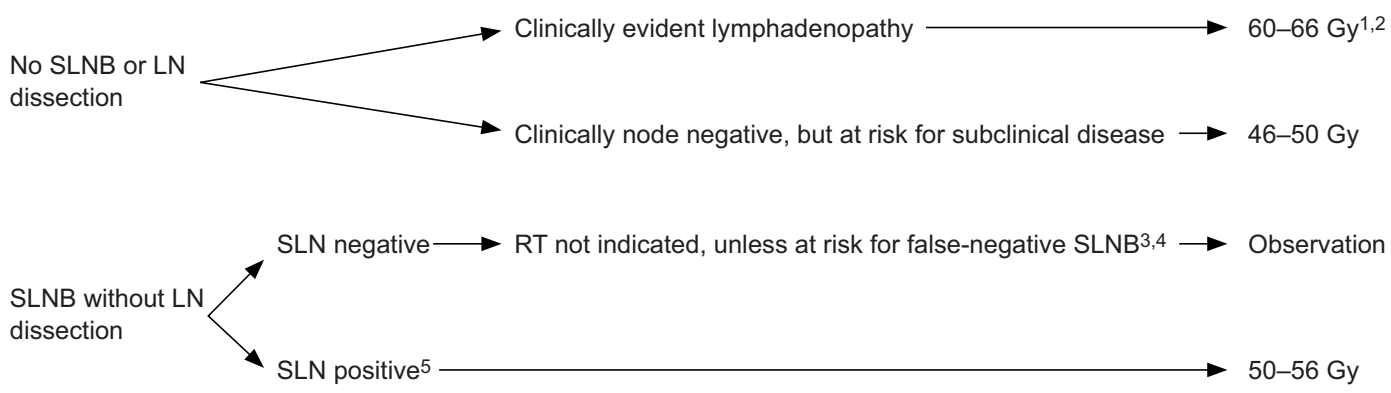

After LN dissection with

multiple involved nodes and/or

50-60 Gy

- Expeditious initiation of adjuvant therapy after surgery is preferred as delay has been associated with worse outcomes.

- All doses are at $2 \mathrm{~Gy} / \mathrm{d}$ standard fractionation. A less protracted fractionation schedule may be used in the palliative setting, such as $30 \mathrm{~Gy}$ in 10 fractions.

- Irradiation of in-transit lymphatics is often not feasible unless the primary site is in close proximity to the nodal bed.

${ }^{1}$ Lymph node dissection is the recommended initial therapy for clinically evident adenopathy, followed by postoperative RT if indicated. 2Shrinking field technique.

${ }^{3}$ Consider RT when there is a potential for anatomic (eg, previous WLE), operator, or histologic failure (eg, failure to perform appropriate immunohistochemistry on SLNs) that may lead to a false-negative SLNB.

4 In the head and neck region, risk of false-negative SLNB is higher due to aberrant lymphatic drainage and frequent presence of multiple SLN basins. If SLNB is unsuccessful, consider irradiating draining nodal basin for subclinical disease.

${ }^{5}$ Microscopic nodal disease (SLN positive) is defined as nodal involvement that is neither clinically palpable nor abnormal by imaging criteria, and microscopically consists of small metastatic foci without extracapsular extension.

${ }^{6}$ Adjuvant RT following lymph node dissection is only indicated for multiple involved nodes and/or the presence of extracapsular extension. Adjuvant RT following LN dissection is generally not indicated for patients with low tumor burden on SLNB or with a single macroscopic clinically detected lymph node without extracapsular extension. 


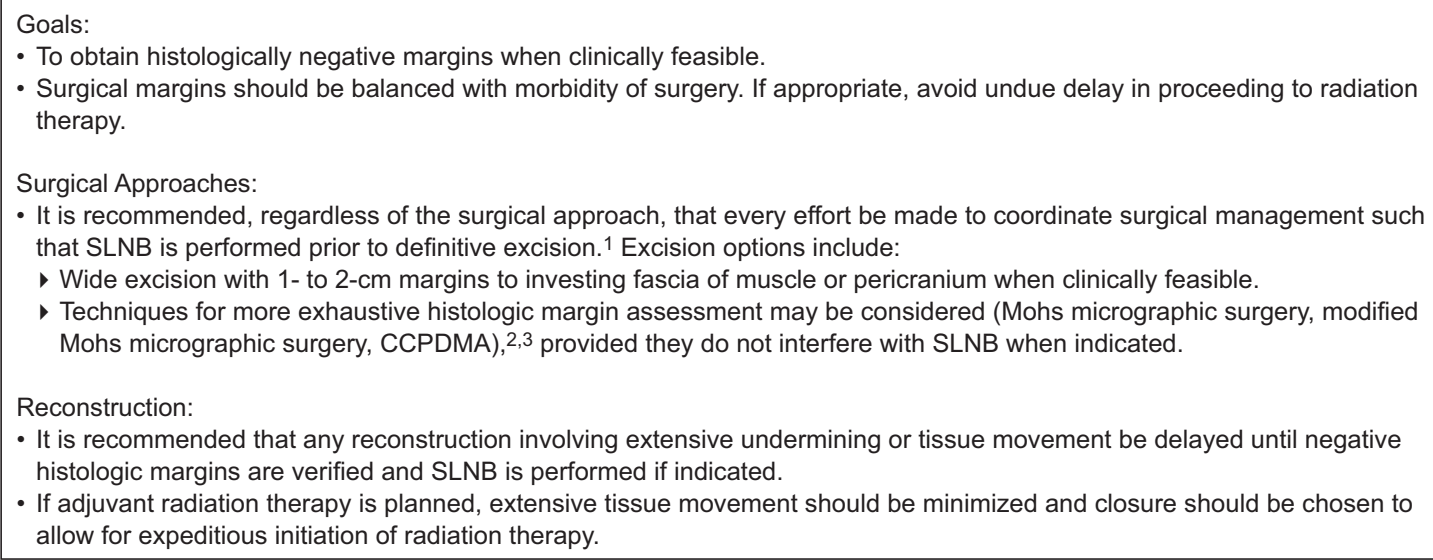




\section{PRINCIPLES OF SYSTEMIC THERAPY 1}

Local Disease:
- Adjuvant chemotherapy not recommended
Regional Disease:
- Clinical trial (preferred)
adjuvant chemotherapy not routinely recommended as survival benefit has not been demonstrated in
- Cisplatin \pm etoposide
Carboplatin \pm etoposide
Disseminated Disease:
- Clinical trial (preferred)
- Avelumab2
- Nembrolizumab2
- As clinical judgment dictates for patients with contraindications to checkpoint immunotherapy:
Cisplatin \pm etoposide
- Carboplatin \pm etoposide
Topotecan
- (CAV): Cyclophosphamide, doxorubicin (or epirubicin), and vincristine

${ }^{1}$ When available and clinically appropriate, enrollment in a clinical trial is recommended. The literature is not directive regarding the specific chemotherapeutic agent(s) offering superior outcomes, but the literature does provide evidence that Merkel cell carcinoma is chemosensitive, although the responses are not durable, and the agents listed above have been used with some success.

${ }^{2}$ Preliminary data from non-randomized trials in patients with MCC demonstrate that rates of durable response are improved with PD-1/PD-L1 blockade compared with cytotoxic therapy. The safety profiles for checkpoint immunotherapies are significantly different from cytotoxic therapies. Consult prescribing information for recommendations on detection and management of immune-related adverse events associated with checkpoint immunotherapies. Clinician and patient education is critical for safe administration of checkpoint immunotherapies. 
the MCPyV-negative group are enriched for cytosine to thymine (C-to- $\mathrm{T}$ ) mutations indicative of UV-damage ${ }^{43-45} \mathrm{MCC}$ incidence increases with age and is more likely to occur in Caucasians compared with other ethnicities. ${ }^{2,4,6,17,19,35}$ In the United States, most patients with MCC are elderly (at least 90\% over the age of 50 years, $>76 \%$ are $\geq 65$ years, $>49 \%$ are $\geq 75$ years $)^{14,17,19,20,22,39}$ and nearly all are Cauca$\operatorname{sian}(\geq 95 \%))^{7,14,15,19,20,22,33,35} \mathrm{MCC}$ is disproportionally more common in immunosuppressed individuals, such as those with organ transplants, lymphoproliferative malignancies (such as chronic lymphocytic leukemia), or HIV infections. ${ }^{14,32,36,46-49}$ Several studies have reported that MCC-specific survival is worse for those with immunosuppression, ${ }^{15,33,50,51}$ although other studies have found no correlation..$^{38,52}$

\section{MCPyV}

In 2008, Feng et $\mathrm{a}^{53}$ identified $\mathrm{MCPyV}$, a novel polyomavirus in MCC tumor tissues. MCPyV was detected in $43 \%-100 \%$ of patient tumors. ${ }^{54-57} \mathrm{Sev}$ eral groups have explored the significance of antibodies to $\mathrm{MCPyV}$ in patients with MCC. ${ }^{58-60}$ In one prospective validation study that included $219 \mathrm{pa}$ tients with newly-diagnosed MCC, quantitation of $\mathrm{MCPyV}$ oncoprotein antibodies (present in about half of MCC patients at diagnosis) was performed to assess the utility of these antibodies for determining prognosis and for early detection of disease recurrence. ${ }^{57}$ This study found that baseline oncoprotein antibody determination may be useful as part of initial workup. In this study, patients who were oncoprotein antibody seronegative at diagnosis had significantly $(42 \%)$ higher risk of recurrence, suggesting that they may benefit from more intensive surveillance. ${ }^{57}$ This study also found that for seropositive patients, the oncoprotein antibody test may be a useful component of ongoing surveillance because a rising titer can be an early indicator of recurrence. ${ }^{57}$

\section{Diagnosis and Workup}

\section{Characteristics and Differential Diagnosis}

The diagnosis of MCC is rarely clinically suspected because the primary tumor lacks distinguishing characteristic features and is often asymptomatic. A study of a cohort of 195 patients with pathologically confirmed MCC found that at presentation, $88 \%$ of MCC tumors were asymptomatic and that correct clinical diagnosis was rare (only 1\%). ${ }^{14}$ Based on clinical impression, $56 \%$ of MCC tumors were initially presumed to be benign cysts/lesions. ${ }^{14}$ Other studies have reported clinical misdiagnoses rates of at least 40\%, and confirm that MCCs are commonly misdiagnosed as benign lesions or nonmelanoma skin cancers, but are also sometimes misdiagnosed as other rare malignant skin tumors. ${ }^{12,13,15,16,61}$ Misdiagnosis is even more prevalent among MCC tumors that are admixed or adjacent to other skin tumors. ${ }^{16,62}$

MCC tumors visualized by hematoxylin-eosin (H\&E) typically contain small round blue cells with sparse cytoplasm, abundant mitoses, and dense core granules in the cytoplasm. ${ }^{40,63-70}$ The histologic diagnosis may also be challenging because MCC is similar to a variety of other widely recognized small round blue cell tumors, including metastatic visceral neuroendocrine carcinomas (eg, neuroblastoma, rhabdomyosarcoma, metastatic carcinoid, desmoplastic small cell tumor, small cell or amelanocytic melanoma, mesenchymal chondrosarcoma, Ewing Sarcoma, small cell lung cancer [SCLC], lymphomas, osteosarcoma). ${ }^{71-76}$ The most difficult differentiation is often between primary MCC and metastatic small cell carcinoma of the lung.

Immunohistochemistry (IHC) has proved useful for distinguishing MCC from other small round cell tumors. In one early study, MCC was correctly diagnosed by light microscopy in 56 of 93 cases $(60 \%)$ but IHC or electron microscopy was needed to diagnose the remaining 37 cases. ${ }^{12}$ Cytokeratin 20 (CK20) and thyroid transcription factor 1 (TTF-1) often provide the greatest sensitivity and specificity to exclude SCLC. ${ }^{66,77-86}$ CK-20 is a very sensitive marker for MCC since it is positive in $75 \%$ to $100 \%$ of primary tumors and rarely positive in SCLC. $66,75,79,81-84,86$ TTF-1 is never positive in MCC but is often positive in SCLC (>80\%) and other primary pulmonary tumors, and sometimes positive in other types of small cell cancers. ${ }^{66,75,81-86} \mathrm{IHC}$ for CK20 and most low-molecular-weight cytokeratin markers is typically positive with a paranuclear "dot-like" pattern. ${ }^{66,74,79,85,87-89} \mathrm{CK} 7$ is expressed in $>80 \%$ of SCLC, but it is less prevalent in MCC. ${ }^{75,87,90-92}$ Neuroendocrine markers such as chromogranin, synaptophysin, CD56, neuron-specific enolase (NSE), and neurofilament are found in most MCC tumors. ${ }^{13,65,66,76,93-97}$ Although the specificity of each of these for MCC is not high, ${ }^{13,40,64,74,75,91,98-100}$ when used together they 
can help identify MCC tumors that are CK20 negative or have other features that make them difficult to diagnose, such as tumors with squamous components or epidermotropism. ${ }^{90,101-106}$ Synaptophysin and chromogranin have been widely used to confirm MCC diagnosis ${ }^{70,88,107-110}$ although a few studies have used other neuroendocrine markers. ${ }^{111}$

\section{Pathology Report}

Synoptic Reporting: Both historically and currently, consistent synoptic reporting of histopathologic parameters for MCCs is not widespread. This is unfortunate because it significantly limits retrospective analysis assessing the diagnostic and prognostic value of specific parameters. For these reasons the American Joint Committee on Cancer (AJCC) strongly encourages synoptic reporting for MCC primary tumor specimens, including but not limited to the parameters needed for determining T-stage. ${ }^{112}$ The College of American Pathologists (CAP) provides a complete synoptic report protocol for cutaneous MCC. ${ }^{113,114}$

Elements of Report: The following parameters are needed for determining AJCC T-stage for MCC: maximum tumor diameter and tumor extension (invasion of fascia, muscle, cartilage, or bone). ${ }^{112}$ The AJCC recommends that maximum tumor diameter should be measured clinically before resection because shrinkage of formalin-fixed tissue may lead to the underestimation of tumor diameter. ${ }^{112}$ Pathological analysis is needed to assess extracutaneous invasion of the primary tumor for the purposes of AJCC staging. ${ }^{112}$ T-staging based on these 2 parameters is supported by analysis of 5-year overall survival of 6,127 patients with local MCC only (clinically and, if known, pathologically lymph node negative). ${ }^{21}$ Other analyses of large patient populations have also shown that primary tumor size $\mathrm{e}^{20,22,38,115}$ and extracutaneous extension have prognostic value (see subsections in the next update of the complete version of the NCCN Guidelines for MCC). ${ }^{116}$ Although not required for staging, AJCC strongly encourages synoptic reporting of primary tumor thickness, measured microscopically from the granular layer of the overlying epidermis to the deepest point of tumor invasion. ${ }^{12}$

In addition to primary tumor size (greatest dimension) and extracutaneous extension, the 2 features needed to assign AJCC T-stage, the CAP protocol for MCC pathology also includes the following primary tumor elements: site (if known), peripheral and deep margin status, and lymphovascular invasion. ${ }^{114}$ Optional CAP elements for the primary tumor include specimen laterality, tumor thickness, mitotic rate, infiltrating lymphocytes (present/absent, brisk/nonbrisk), growth pattern (nodular, infiltrative), and presence of second malignancy. ${ }^{114}$ The prognostic value of histopathologic features is a topic of much debate. As will be described in greater detail in the next update of the complete version of the NCCN Guidelines for MCC (to be posted online at NCCN.org), an emerging body of literature suggests that these primary tumor features may provide relevant prognostic information with regards to survival and/or sentinel lymph node positivity in MCC.

\section{NCCN Recommendations for Diagnosis and Pathology Report}

Initial workup of a suspicious lesion starts with a complete examination of the skin and lymph nodes followed by biopsy of the primary tumor. Initial diagnosis of MCC in the primary lesion by H\&E staining should be confirmed by performing IHC staining. Because MCC is often misdiagnosed, diagnosis should be confirmed by a pathologist experienced in distinguishing MCC from cutaneous simulants and metastatic tumors. An appropriate immunopanel should include CK-20 and TTF-1. Other IHC neuroendocrine markers such as chromogranin A, synaptophysin, neurofilament protein, NSE, and CD56 may be used in addition to CK-20 and TTF-1 to exclude other diagnostic considerations.

The goals of the primary tumor excision specimen analysis are 1) to accurately diagnose and to distinguish it from cutaneous simulants and metastatic tumors; 2) to provide complete pathologic tumor characteristics for staging according to recommended AJCC and CAP guidelines; and 3) to standardize pathologic data collection to further understand the critical biologic features that impact MCC behavior and prognosis. "Principles of Pathology" in the NCCN Guidelines algorithm (see page 749) outlines the elements that should be included in a pathology report. In accordance with the AJCC, the NCCN panel agrees that synoptic reporting is preferred. At a minimum, the pathology report should include tumor size, peripheral and deep margin status, lymphovascular invasion, and extracutaneous extension to the bone, muscle fascia, or cartilage, as these features 
may prove to have prognostic value. The NCCN panel strongly encourages reporting of the following additional primary tumor features: tumor thickness (Breslow, in $\mathrm{mm})$, mitotic rate $\left(\# / \mathrm{mm}^{2}\right.$ preferred, \#) high-powered field, or MIB-1 index), tumor growth pattern (nodular or infiltrative), tumor-infiltrating lymphocytes (not identified, brisk, non-brisk), and the presence of a second malignancy such as concurrent squamous cell carcinoma within the pathologic specimen itself.

\section{Imaging}

The utility of imaging as part of baseline staging for MCC is an issue debated in the literature. A number of retrospective analyses have reported data on detection and appearance of MCC tumors using various imaging methods, including conventional $\mathrm{x}$-ray, ${ }^{12,67,117} \mathrm{CT},{ }^{12,117-120}$ ultrasound, ${ }^{12,120,121}$ MRI, ${ }^{67,117,120,121}$ scintigraphy, ${ }^{122-124}$ and PET or PET/ CT. ${ }^{120,121,125-137}$ Among these imaging methods, those with the most reported data in patients with MCC are CT, MRI, and FDG-PET or FDG-PET/CT. For all 3 of these modalities there are reports showing detection of MCC primary tumors, lymph node metastases, and distant metastases found in a wide range of anatomic locations. ${ }^{12,67,117,118,121,126,127,129,133,137}$ Although ample evidence exists that these methods have identified MCC tumors in a variety of anatomic locations, this evidence alone does not necessarily imply that these imaging methods will detect all MCC tumors.

A number of studies have attempted to determine the utility of specific imaging methodologies for detecting MCC tumors, either in terms of the sensitivity, specificity, and positive/negative predictive value, or in terms of the number of patients who were upstaged or downstaged or had their management changed due to imaging findings. ${ }^{119-121,125-130,132-137}$ Many of these studies are limited by small sample size $(\mathrm{n}<30),{ }^{120,125-127,130,132,133,135,136}$ and did not consistently use pathologic confirmation as a standard of reference for determining whether imaging results were true or false positives or true or false negativ es. ${ }^{119,120,125,127,133,136,137}$ Regarding the use of MRI for detection of MCC, data on the sensitivity, specificity, and impact on staging or management are very limited. For CT and PET/CT, however, these metrics have been calculated in multiple studies, as described in the next section.
CT: Only a few studies have evaluated the utility of CT (separately from other imaging modalities) for detection of MCC tumors. ${ }^{119,121}$ In one study of 35 patients with imaging and biopsy-proven MCC, Gupta et $\mathrm{al}^{119}$ compared the results of baseline scans with the results of sentinel lymph node biopsy (SLNB; when available), further radiologic tests, or clinical follow-up for 6 months. In this study, the calculated sensitivity of baseline imaging for detection of lymph node metastases was only $20 \%$, with negative imaging results in 16 of 20 patients with regional disease. ${ }^{119} \mathrm{~A}$ separate study compared CT results with pathology from SLNB or lymph node dissection (LND) in 69 patients. ${ }^{121}$ Whereas scans of lymph node basins correctly identified 15 patients with nodal involvement ( 15 true positives), and correctly identified 36 nodal basins without MCC (36 true negatives) with only one false positive, the sensitivity of CT for detecting lymph node metastases was low (47\%) due to negative imaging results in 17 of 32 patients who were shown to have nodal disease based on SLNB or LND (17 false negatives). ${ }^{121}$ In this study CT imaging not only failed to detect micrometastases $(<1 \mathrm{~mm} ; \mathrm{n}=6$ patients), but also larger lymph node metastases, including single node positivity in 6 patients and multiple positive nodes in 5 patients. ${ }^{121}$ To determine whether CT imaging may provide useful nodal staging information despite low sensitivity, results were analyzed for the subset of patients who had all 3 tests (imaging, clinical exam, and pathology from SLNB/LND; $n=61) .121$ Although $\mathrm{CT}$ and clinical exam results did not always agree, this analysis showed that CT did not provide any additional useful staging information because CT results supported incorrect restaging (compared with pathology) with the same frequency that clinical exam resulted in incorrect restaging.

Gupta et $\mathrm{a}^{119}$ also reported the results from 36 CT scans for the detection of distant metastatic disease. Although 4 of the suspicious findings were confirmed ( 4 true positives) and all 16 patients with negative results did not show any signs of progression within the first 6 months (16 true negatives, 0 false negatives), there were 17 suspicious findings that did not progress during follow-up and were deemed false positives. The calculated specificity was $48 \% .{ }^{119}$ Thus, although CT imaging is widely used to screen for distant MCC metastases, data supporting the sensitivity and specificity of this approach are limited. 
FDG-PET/CT: Compared with CT imaging, there are many more studies on the utility of FDG-PET/ CT for detecting MCC tumors. ${ }^{120,121,125-130,133-137}$ In studies in which FDG-PET/CT was compared with subsequent pathologic nodal evaluation (SLNB or LND), the calculated sensitivity of FDG-PET/CT was markedly different across studies. ${ }^{121,129,135}$ Colgan et $\mathrm{a}^{121}$ retrospectively analyzed 33 patients who received full-body FDG-PET or FDG-PET/CT prior to SLNB or LND. Imaging sensitivity was $83 \%$ based on correct identification of 10 of 12 positive lymph nodes ( 2 false negatives) and specificity was $95 \%$ based on correct identification of 20 of 21 diseasefree lymph node basins ( 1 false positive). Whereas nodal disease was detected by clinical exam in 4 of 12 patients with positive nodal pathology, FDG-PET or FDG-PET/CT imaging identified 6 positive lymph node basins that were missed by clinical exam. ${ }^{121}$ In contrast, a retrospective analysis by Hawryluk et al, ${ }^{129}$ including 36 patients who had FDG-PET/CT before SLNB, found that FDG-PET/CT detected nodal disease in only 3 of 21 patients (14\%) who had positive SLNB results. Low sensitivity for detecting clinically occult lymph node metastases was also reported in a study by Liu et $\mathrm{al}^{135}$ that included 16 patients who received FDG-PET/CT prior to SLNB: FDG-PET/CT detected regional disease in only 1 of 10 patients with positive SLNB results even though 8 patients were found to have measurable lymph node metastases $(1-15 \mathrm{~mm})$ by histologic analysis. ${ }^{135}$ The wide range of reported specificity may in part be due to differences in the extent of disease across the patient populations analyzed. Hawryluk et al ${ }^{129}$ included a high percentage of patients whose nodal disease was only detectable by IHC and thus unlikely to be detected by FDG-PET/CT. Another study of 18 patients with histologically proven MCC (including a wider range of stages) found that all MCC sites histologically proven to be $>5 \mathrm{~mm}$ in diameter were detectable by FDG-PET/CT. ${ }^{126}$ This study, which was not limited to analysis of lymph node metastases, found that FDG-PET/CT detected 13 of 14 histologically confirmed MCC tumors (sensitivity 94\%).

Analyses using less stringent criteria for verifying imaging results (ie, allowing clinical or imaging follow-up as a standard for comparison) and that included a wide range of disease stages have reported overall sensitivity and specificity of FDG-PET/CT for detecting MCC tumors ranging from $86 \%-100 \%$ and $89 \%-100 \%$, respectively. ${ }^{120,125,127,131,133,138}$ Sources of FDG-PET/CT false positivity (non-MCC related FDG uptake excluded by clinical and histologic correlation), include nonspecific adenopathy, postoperative inflammation in tumor bed and lymph node basin, preexisting sarcoidosis, lung carcinoma, lymphoma, and newly-diagnosed non-Hodgkin's lymphoma. ${ }^{129}$ A number of retrospective studies and one prospective study have reported that results from FDG-PET/CT scans at initial presentation impacted baseline staging in 6\%-39\% and changed management in $6 \%-37 \%$ of patients with MCC. ${ }^{128-130,133,138}$ Three of these studies included sample sizes of more than 50 patients. ${ }^{128,129,138}$ In a review of 102 patients by Siva et al, ${ }^{128}$ FDG-PET changed the stage and primary treatment (modality or intent) in $22 \%$ of patients, with $17 \%$ of patients upstaged due to the discovery of nodal or distant metastases and 5\% downstaged. FDG-PET results also altered the radiation technique or dose for another $15 \%$ of patients (change in management for $37 \%$ of patients). ${ }^{128}$

Similar results were reported in another review of 97 patients by Hawryluk et al, ${ }^{129}$ in which $16 \%$ of patients were upstaged by baseline FDG-PET/CT scans. A prospective study of 58 patients imaged before treatment found that FDG-PET results upstaged $26 \%$ of patients (no downstaging), and altered management in $28 \%$ of patients (treatment modality, intent, extent, or dose). ${ }^{138}$ It is important to note that for all of the abovementioned studies, FDG-PET was only used in patients who presented with features indicating high risk of recurrence or clinical suspicion for nodal/distant spread. These data do not imply that all patients with MCC should be screened with FDG-PET/CT at initial diagnosis. Most of the changes in stage and management based on FDGPET imaging results were due to discovery of more extensive lymph node involvement or distant metastatic disease, suggesting that FDG-PET imaging may be more useful in patients with more (clinically) advanced disease at presentation. Indeed, several studies have reported average FDG-PET maximum standardized uptake values (SUVmax) detected by FDG-PET suggesting a possible trend toward higher uptake in MCC lymph node metastases compared with primary lesions, and a trend toward even higher uptake in non-lymph node metastases (eg, bone, liver, brain). ${ }^{126,129,137}$ Multiple studies assessing the utility of FDG-PET/CT for MCC staging and surveil- 
lance have also reported identification of previously undetected secondary cancers, and some of these findings changed management. ${ }^{121,125-127,137}$

Some evidence suggests that FDG-PET/CT may be more useful than CT in detecting nodal and distant MCC. In the retrospective analyses by Colgan et $\mathrm{al},{ }^{121}$ in which CT and SLNB results were compared in 69 patients and FDG-PET and SLNB results were compared in 33 patients, the calculated sensitivity of FDG-PET was notably better than that for CT $(83 \%$ vs $47 \%$ ). The upstaging results from the retrospective analysis by Siva et $\mathrm{al}^{128}$ and from the prospective study by Poulsen et al ${ }^{138}$ are particularly notable because in addition to clinical exam, the staging prior to FDG-PET was based on CT of the draining nodal basin, and for the prospective study, CT of the chest and abdomen as well. Both of these studies found FDG-PET/CT positive lymph nodes not detected by $\mathrm{CT}$, and the latter also identified distant metastases not apparent on CT scans. ${ }^{128,138}$ Hawryluk et al ${ }^{129}$ also noted that FDG-PET/CT identified bone metastases $(n=10)$ that were all not detected by CT. ${ }^{129}$

The utility of FDG-PET/CT is likely limited for identifying primary tumors in patients who present with nodal disease but no clinically apparent primary. In one study of patients who received a scan before primary excision, FDG-PET/CT detected 41\% (12/29) of clinically apparent primary tumors. ${ }^{129}$ Nonetheless FDG-PET/CT may be useful in patients with unknown primary tumors for the purpose of screening for clinically occult nodal and distant metastatic disease.

Detection of Distant Metastatic Disease: Many retrospective studies have reported on the pattern of MCC metastatic spread to distant sites, based on large patient databases that include data from various points in the development of the disease (eg, diagnosis, assessment of response to treatment, restaging, follow-up, and sometimes postmortem). ${ }^{12,18,26,52,61,117,129,133,137,139-141}$ Based on these analyses, distant metastatic MCC is most likely to arise in distant lymph nodes or skin, bone/bone marrow, lung/pleura or liver. The second tier of likely locations include the pancreas, adrenal glands, brain, kidneys, subcutaneous tissue or muscle. Rarer sites of distant metastasis include the breast, gastrointestinal tract, testes, heart, retroperitoneum and peritoneal cavity, and a variety of other locations.

\section{NCCN Recommendations for Imaging During Work-} up: For patients with biopsy-confirmed MCC, additional workup may include imaging studies as clinically indicated. Given that reports in the literature have found that even with FDG-PET/CT, clinically occult lymph node metastases are not infrequently undetectable by imaging, ${ }^{121,129,135}$ the NCCN panel does not generally recommend imaging for identifying subclinical or regional disease in patients who have no clinical signs of nodal spread. SLNB is considered the most reliable staging tool to identify subclinical nodal disease. Total body imaging is not routinely indicated, but is encouraged whenever metastatic or unresectable disease is suspected based on H\&P findings. Specific examples of when imaging would be clinically indicated include presence of symptoms (eg, tender nodes) or abnormal lab results. Identification and imaging of palpable nodes is important, although size is not necessarily an indicator of node positivity, which is why pathologic evaluation of lymph nodes is more important. Imaging may be useful in identifying and quantifying distant metastases as clinically indicated due to the metastatic potential of this tumor. Imaging may also be indicated to evaluate for the possibility of a skin metastasis from a noncutaneous carcinoma (eg, small cell carcinoma of the lung), especially in cases where CK-20 is negative, and to screen for secondary malignancies. Consultation with the surgical team is recommended, as surgeons may request imaging to better understand the anatomy of the disease for surgical planning.

Recommended imaging modalities include brain MRI with contrast and neck/chest/abdomen/pelvis CT with contrast or whole body FDG-PET/CT. FDG-PET/CT scanning is widely used for diagnostic imaging of MCC and may be preferred in some instances, such as a primary tumor location on an extremity. CT or MRI with contrast may be used if whole body FDG-PET/CT is not available. Based on the pattern of metastases for MCC, whole body FDG-PET/CT or neck/chest/abdomen/pelvis CT are recommended when distant metastatic disease is suspected, but the use of brain MRI in this setting varies among NCCN panel members. Whereas some panel members prefer to include brain MRI when screening for distant metastatic disease in patients with nodal involvement, others reserve this test for cases that have an indication of brain metastases or in which widespread systemic disease has been detected. 


\section{Staging and Initial Treatment}

After initial workup, treatment is primarily dependent on accurate histopathologic interpretation and on microstaging of the primary lesion. A multidisciplinary panel is recommended to ensure high-quality coordinated care for patients diagnosed with this rare and challenging disease. ${ }^{142}$

Surgery is the primary treatment modality for MCC, and it is needed for accurate microstaging of both the primary lesion and regional disease. However, there is some variability among individual clinicians and NCCN Member Institutions regarding the management of patients with MCC due to the absence of prospective clinical trials. Therefore, the MCC guidelines are suitably broad to reflect all the approaches taken by participating NCCN Member Institutions.

The current AJCC staging system ( $8^{\text {th }}$ Edition) is based on an updated analysis of 9,387 cases of MCC from the National Cancer Data Base (NCDB) with a median follow-up of 28.2 months. $^{21}$ The NCCN staging of MCC parallels the AJCC guidelines and divides presentation into local, regional, and disseminated disease. ${ }^{112}$ The "Pathology Report" section describes the data supporting the primary tumor features relevant to determining $\mathrm{T}$-stage, as well as additional features that the NCCN panel recommends be included in characterization of the primary tumor. Clinical exam and initial imaging studies (if indicated) are used to make an initial determination of the clinical $\mathrm{N}$-stage and $\mathrm{M}$-stage, which in turn determines the recommended approach for evaluating pathological nodal status. Although there is evidence that among patients with clinically apparent nodal disease at presentation, those with unknown primary have better outcome than those with synchronous known primary, ${ }^{21,33,143-145}$ and these findings are reflected in the AJCC staging system, ${ }^{112}$ the NCCN recommendations for pathologic evaluation of nodal status and management of the nodal basin are the same for both of these groups of patients.

\section{SLNB}

Large retrospective analyses $(n>100)$ or meta-analyses of SLNB in patients with clinically node-negative localized MCC, have reported rates of SLN positivity ranging from $30 \%-38 \% .{ }^{15,38,119,146-150}$ As discussed in the sections on the elements of the pathology report, there are a number of primary tumor characteristics that have been proposed, although debated, to be predictive of SLN positivity, including primary tumor diameter, thickness, mitotic rate, anatomic location, LVI, and TILs. ${ }^{38,151-154}$ Nonetheless, despite many analyses of prognostic factors based on large patient samples, no low-risk category has been identified for which the rate of SLN positivity is negligible. ${ }^{38,151,152-154}$ Results from retrospective studies evaluating the prognostic value of SLN status have varied. Some studies showed significant association between SLN negativity and lower risk of recurrence ${ }^{119,146,154}$ and improved MCC-specific or overall survival. ${ }^{154,155}$

Conversely, others findings show no significant prognostic value of SLN status, ${ }^{150,151}$ only nonsignificant trends toward improved outcomes in patients with negative SLNB results, ${ }^{38}$ significant correlation between SLN status and some but not all outcomes, ${ }^{148}$ or significant correlation with outcome only in the subpopulation that did not get adjuvant treatment to the nodal bed. ${ }^{149}$ Variability in these results may in part be due to differences in application of SLNB techniques leading to differences in rates of successful identification of the SLN and differences in the rates of false-negative SLNB results, or differences in treatment practices that impact the fraction of patients with negative SLNB results who nonetheless receive adjuvant treatment (eg, RT), as well as the fraction of patients with positive SLNB results who receive complete LND (CLND) and/or other adjuvant treatments. Reported rates of regional relapse in patients with negative SLNB results range from $5 \%-12 \%$, with corresponding false-negative rates between $17 \%-21 \% .{ }^{148,149,154}$ Some studies have reported complicated drainage patterns for MCCs occurring in the head and neck, and many retrospective analyses have found that multiple SLNs were identified in some patients, ${ }^{135,148,149,154,156}$ suggesting that failure to identify all the relevant SLNs may have contributed to the relatively high rates of falsenegative SLNB results.

Regarding the utility of SLNB for management of patients with clinically node-negative disease, another issue of debate is whether the SLNB procedure itself offers some protection against recurrence, progression, or death from disease. One retrospective study of patients with clinical stage I/II MCC found, by univariate and multivariate analysis, that the 474 patients who underwent SLNB had improved 5-year 
MCC-specific survival compared with the 719 patients who did not undergo SLNB (nodal observation only), although the actual difference in rates was small (79\% vs $74 \%) .{ }^{155}$ Consistent with these findings, another multivariate analysis of a large population database (Kaiser Permanente Northern California) found that compared with patients who had no pathologic nodal evaluation $(n=129)$, those with SLNB alone $(n=26)$ or SLNB plus LND $(n=40)$ had lower risk of all-cause mortality, and that SLNB plus LND was also associated with improved MCC-specific mortality, although no significant association with locoregional recurrence rate was seen. ${ }^{33}$ There is insufficient information in these large population-base databases to ascertain whether these apparent associations are due to the SLNB procedure itself or due to subsequent management choices informed by the results of pathologic nodal evaluation. Smaller retrospective studies using institutional databases with more complete patient data have found that among patients presenting with clinically node-negative MCC, SLNB is not significantly associated with improved locoregional control or overall survival, ${ }^{15,51}$ although one did report significantly longer overall survival for patients who underwent SLNB. ${ }^{157}$

SLNB Pathology: In patients with MCC, IHC analysis has been shown to be effective in detecting lymph node metastases not detected by hematoxylin and eosin (H\&E). ${ }^{129,158-160}$ Among the retrospective studies that included information about SLN histologic analysis in patients with MCC, most of those published in the past 10 years and a few published earlier included IHC with CK-20 as part of routine screening. ${ }^{135,151,152,154,157-159,161-164}$ Some studies have also reported using other additional IHC stains for histologic analysis of SLNs, pancytokeratins (AE1/AE3, CAM5.2) and/or other antibodies sometimes used for differential diagnosis of primary MCC lesions, such as chromogranin A, thyroidtranscription factor-1, neurofilament and synaptophysin. ${ }^{135,151,152,154,157-159,162}$

A detailed histologic analysis of SLN disease in 64 patients identified 5 patterns of MCC spread. ${ }^{165}$ The most common pattern (59\% of cases) was a solid, sheet-like nodule detectable by H\&E (IHC needed only for confirmation of MCC), and was associated with higher likelihood of extracapsular extension (ECE), identification of more than one positive lymph node, and the poorest outcomes (OS). ${ }^{165}$
The 4 other patterns described (patterns 2-5) were seen in lymph nodes with lower tumor burden, usually $<200$ tumor cells per LN. Three of these patterns were sometimes detectable by $\mathrm{H} \& \mathrm{E}$ alone but sometimes required IHC for detection. These 3 were described as "parafollicular" (nonsolid dispersed cells clustered in the parafollicular lymph node cortex), "sinusoidal" (variable numbers of isolated cells in the subcapsular and draining lymph node sinuses), and "perivascular hilar" (cells clustered around larger vessels in the lymph node hilum). The fifth pattern, seen in $16 \%$ of cases, was described as scattered single parenchymal tumor cells, and IHC was always required for detection.

\section{Clinically Node-Negative Disease: NCCN Recommendations for Further Workup}

SLNB is considered the most reliable staging tool for identifying subclinical nodal extension. SLNB is recommended for all patients with clinically nodenegative disease who are fit for surgery. Although very important for staging and for guiding treatment of MCC, the impact of SLNB on overall survival is unclear. Essentially all participating NCCN Member Institutions use the SLNB technique routinely for MCC. The NCCN Panel believes that by identifying patients with positive microscopic nodal disease and then performing full LNDs and/or RT, the care of regional disease in this patient population is maximized. SLNB should be performed prior to surgical removal of the primary, with special care taken in the head and neck region where drainage patterns are often complex and can lead to unreliable SLNB results (risk of false negatives). As for other skin cancers, SLNB is almost always performed at the time of initial surgical removal of the primary tumor.

In patients with MCC, IHC analysis should be included in the SLNB evaluation in addition to H\&E sections to reduce risk of false negatives. CK20 immunostaining should be included in the pathologic assessment of sentinel lymph nodes evaluated for MCC to facilitate accurate identification of micrometastases. An appropriate immunopanel may also include pancytokeratins (AE1/AE3), depending on the immunostaining pattern of the primary tumor, and particularly if $H \& E$ sections are negative. Some NCCN Member Institutions routinely use both CK-20 and pancytokeratin stains to evaluate SLN samples to ensure detection of MCC metastases 
because results from these 2 markers are not always consistent. The pathology report should also include the tumor burden of each node ( $\%$ of node), tumor location (eg, subcapsular sinus, parenchyma), and the presence or absence of extracapsular extension.

Patients with positive SLNB results should receive baseline imaging, if not already performed, to screen for and quantify regional and distant metastases. Although for most patients imaging results will be negative, especially if there is low tumor burden in the sentinel node, it is important to confirm staging, and baseline scans are useful for comparison in the event of a suspected recurrence. Recommended imaging modalities for detecting regional or distant metastases are described in the section entitled "NCCN Recommendations for Imaging During Workup" (see page 758). If a distant metastasis is detected, management should follow the M1 pathway.

\section{Clinically Node-Positive Disease: NCCN Recommendations for Further Workup}

A clinical $\mathrm{N}+$ diagnosis (palpable lymph nodes) should be confirmed using fine-needle aspiration or core biopsy with an appropriate immunopanel. Samples from palpable lymph nodes should be subjected to the same battery of tests recommended for SLN pathology (see section entitled "SLNB Pathology," page 760). An open biopsy may be considered to confirm a negative initial fine-needle aspiration or core lymph node biopsy if clinical suspicion remains high. If negative results are confirmed, the patient should be managed as clinical NO. If initial or subsequent lymph node biopsy results are positive, imaging studies are recommended if not already performed to evaluate the extent of lymph node and/or visceral organ involvement. Recommended imaging modalities for detecting regional or distant metastases are described in the section entitled "NCCN Recommendations for Imaging During Workup" (see page 758). If a distant metastasis is detected, management should follow the M1 pathway.

For discussion of initial management of primary tumor and regional lymph nodes with surgery and/ or definitive radiation therapy (RT), see complete NCCN Guidelines for MCC, available online at NCCN.org.

\section{Postoperative Radiation and Chemotherapy for Locoregional Disease}

\section{Postoperative Radiation}

Numerous retrospective studies and meta-analyses of data from retrospective studies have attempted to determine whether postoperative RT improves outcomes in patients with MCC. Some of these have found that postoperative RT is associated with improved freedom from recurrence and survival compared with surgery alone, $3,26,154,166-172$ others found no significant correlations with outcomes, ${ }^{15,30,149,164,173,174}$ and many reported mixed results, finding that adjuvant RT was significantly associated with improvements in some but not all outcome measures, and/ or showing nonsignificant trends for some outcome measures. . $8,31,52,115,128,141,175-184$ For most of these studies the results are difficult to interpret because the population included a range of MCC stages, a mix of primary and recurrent MCC cases, a variety of surgical procedures prior to RT (ie, mix of wide local excision and biopsy, negative and positive margins; SLND, CLND, or none), and a mix of patients who received RT to the primary site only, nodal basin only, or both. Therefore it is unclear whether the differences in results across studies is due to differences in the patient population, treatment prior to RT, or details about the target site and RT dosing.

To try to assess the value of adjuvant RT in specific clinical contexts, some retrospective studies included subgroup analyses, although in many cases the small sample sizes of the subgroups precluded meaningful statistical analysis. A number of retrospective studies have focused on patients with locoregional disease (no distant metastases), ${ }^{52,141,171,178,180,182}$ including several large retrospective studies $(n>100)$ that used multivariate analysis to determine whether postoperative RT was correlated with outcomes in patients with locoregional disease. ${ }^{52,141,180,182}$ As for the larger population-based studies that included patients with distant metastatic disease, results of these analyses varied, with some showing that the addition of RT reduced risk of recurrence and/or improved survival, while others found no significant association with these outcomes. ${ }^{52,141,180,182}$

Data to inform decisions about adjuvant RT in more specific clinical contexts are far less abundant. Jouary et $\mathrm{al}^{185}$ conducted the only randomized trial to date in MCC. Patients with stage I disease treated by wide excision and RT to the tumor bed were 
randomized to adjuvant regional RT or observation. The trial was closed prematurely due to a drop in recruitment attributed to the advent of sentinel node dissection. Analysis of 83 patients showed no improvement in PFS or OS with adjuvant radiation, but a significant decrease in risk of regional recurrence was found compared with the observation group ( $0 \%$ vs $16.7 \% ; P=.007$ ). Aside from the randomized trial described, several retrospective studies have evaluated the association between adjuvant RT and outcomes in patients with node-negative disease. ${ }^{115,154,164,173,176,182-184}$ Unfortunately the results for both risk of recurrence/progression and survival (disease-specific survival or OS) are inconsistent, with some but not all studies showing improvements with postoperative RT. ${ }^{154,164,173,176,182-184}$ Therefore it is not clear whether or not postoperative RT provides clinical benefit for patients with pathologically nodenegative disease. It is important to note that for most of these studies adjuvant RT was sometimes administered to both the primary site and the nodal basin even in SLN-negative cases, and the impact of RT to the primary tumor bed versus the nodal basin was often not evaluated separately. The clinical value of RT to the primary tumor bed is unclear because results are inconsistent among the studies in which patients with SLN-negative disease received RT to the primary bed only, and results are also inconsistent among the studies that evaluated RT to the primary tumor bed separately from RT to the nodal basin, with some finding that postoperative RT improves disease control and survival and others finding no statistically significant associations. ${ }^{31,154,181,182,186}$

Several studies have attempted to determine whether clinical benefit from postoperative RT is associated with the size of the primary tumor, but results have varied across studies, with one finding that postoperative RT was associated with improved locoregional control (LRC) and OS for all primary tumor size categories, ${ }^{174}$ but another finding that RT-associated improvement in survival was significant for some but not all primary tumor size categories. ${ }^{169}$ Several retrospective studies have tried to determine whether benefit from postoperative RT depended on margin status (after excision of the primary), but results did not agree. ${ }^{31,182}$ One retrospective study focused specifically on very low risk stage I patients $(n=46)$, defined as those with primary tumor size $\leq 2 \mathrm{~cm}$, negative pathologic margins, negative SLNB, and no im- munosuppression, found that adjuvant RT was associated with reduced risk of local recurrence ( 0 vs $26 \%$; $P=.02$ ) but had no impact on OS or disease-specific survival. ${ }^{183}$ Therefore, despite all these analyses, it is still unclear how to identify patients with MCC most likely to benefit from postoperative RT.

Regarding the clinical benefit of RT for patients with node-positive MCC, results from retrospective analyses vary widely between studies. ${ }^{115,141,164,175,182,184}$ An NCDB analysis including 6,908 patients found that adjuvant RT improved OS compared with surgery alone for patients with stage I or stage II MCC, but not for those with stage III disease. ${ }^{115} \mathrm{~A}$ retrospective study from UCLA $(n=87)$ had similar results, reporting that postoperative RT was associated with improved survival in patients with stage I/II disease, but not for the whole population (including all stages). ${ }^{184}$ In contrast, a retrospective study from Moffitt Cancer Center $(\mathrm{n}=171)$ found that postoperative RT improved locoregional control and disease-specific survival in patients with pathologic or clinically positive nodes, but not in node-negative patients. ${ }^{182}$ A key difference between these studies is that while patients in the NCDB and UCLA study likely received a wide variety of surgical and RT interventions, patient selection in the Moffitt study was much more stringent, with most patients treated with wide local excision with $1-2 \mathrm{~cm}$ margins $(n=168 / 170)$, and all patients received pathologic nodal staging (SLNB for clinically node-negative, TLND for clinically node-positive patients). ${ }^{184}$ 115,182 The results of the Moffitt study are noteworthy because LRC was improved by postoperative RT in patients with SLN-positive (clinically nodenegative) disease (LRC, 3 years, for surgery alone vs surgery plus RT: $27 \%$ vs $76 \% ; P<.001$ ), even though more than half of these patients received CLND $(n=30 / 52)$, and in patients with pathologically confirmed clinical node-positive disease (LRC, 3 years: 0 vs $75 \% ; P=.003)$, even though all these patients had received TLND $(\mathrm{n}=17 / 17) .{ }^{182}$

\section{Postoperative Systemic Therapy}

There are many studies that report outcomes for a small number of patients, but high-quality clinical data on adjuvant systemic therapy options for MCC are lacking, and almost all the data are for postoperative chemotherapy combined with radiation. ${ }^{187,188}$ Most of the data are from retrospective studies, and 
assessment of efficacy is based on data pooled from patients with a range of stages, a variety of prior/concomitant therapies (eg, different types of prior surgery and prior or concurrent RT), and MCC treatment with a variety of systemic therapy agents and regimens. Even for the best available retrospective studies - those with the largest sample sizes and that use multivariate analyses to control for the many factors that may also impact outcome- the ability to assess the impact of postoperative systemic therapy on outcomes was often seriously limited by the fact that only a small minority of patients received chemotherapy. For most of the studies in which some subset of patients received postoperative chemotherapy, often in combination with adjuvant RT, use of chemotherapy was not associated with reduced risk of recurrence or distant metastasis, nor was chemotherapy associated with improved survival. 27,30,33,115,167,172, $174,181,189$ One study found that adjuvant chemotherapy was associated with worse survival based on univariate analysis, but the association was not significant by multivariate analysis. ${ }^{189}$ Several studies found that postoperative chemoradiation did not improve outcomes compared with postoperative radiation, ${ }^{52,172,174}$ including one study in which results from a prospective trial of chemoradiation (carboplatin and etoposide) in 40 patients with stage I-III disease were compared with historical controls $(n=62)$ treated with postoperative RT. ${ }^{190}$

A study of 4,815 patients with MCC in the NCDB that included 393 patients treated with surgery and postoperative chemoradiation and $97 \mathrm{pa}-$ tients with surgery and postoperative chemotherapy found by multivariate analysis that, relative to surgery alone, postoperative chemoradiation improved OS but postoperative chemotherapy (without radiation) had the opposite effect. ${ }^{172}$ In a multivariate analysis of the subset of the 2,820 patients who received postoperative therapy, there was a nonsignificant trend toward improved OS with postoperative chemoradiation compared with postoperative RT alone $(P=.08)$, but this difference was significant in the subset of patients who had positive margins $(P=.03)$ and in the subset with primary tumor size $\geq 3 \mathrm{~cm}(P=.02) .{ }^{172}$ These results suggest that although postoperative chemotherapy without radiation is unlikely to improve outcomes, postoperative chemoradiation may have a role in particularly high-risk cases in which residual disease is present after surgery.
The most common systemic therapy regimen used for adjuvant treatment of regional disease is cisplatin or carboplatin with or without etoposide, ${ }^{27,30,52,174,189,190}$ although information about the agents used was not available from the NCDB analysis (described above) showing that postoperative chemotherapy may provide clinical benefit in certain high-risk patients. ${ }^{172}$ Although not routinely recommended for adjuvant treatment of regional disease, if used in select cases the panel recommends cisplatin or carboplatin with or without etoposide.

\section{NCCN Recommendations for Postoperative Management of the Primary Tumor}

After surgery, patients may undergo postoperative RT of the primary site or consider observation. The currently available clinical evidence on the efficacy of postoperative RT is inconsistent across studies, even for the lowest risk groups, so it is unclear how to identify candidates most likely to benefit from postoperative radiation of the primary tumor site. In the absence of clear consistent data regarding which patient- or disease-specific factors are associated with clinical benefit from postoperative RT, the panel suggests that observation may be reasonable for patients with small primary lesions $(\mathrm{eg},<1 \mathrm{~cm})$ that have been widely excised and who present with no adverse risk factors such as lymphovascular invasion (LVI) or immunosuppression. LVI and immunosuppression are risk factors of particular concern because they are associated with many-fold increased risk of recurrence or progression, at least in some studies. . $^{50,59,108,110,141,149,182,191}$ Associations with survival have been reported in some but not all studies evaluating the prognostic value of LVI $^{29,34,108,128,170,192-194}$ and immunosuppression. $15,33,38,51,52,59,110,154,195-197$

Adjuvant RT to the primary site is generally recommended for all other cases, especially for patients with microscopic or grossly positive margins or other risk factors for recurrence. Efforts should be made to avoid delay of adjuvant RT if planned because delay between the time of surgery and RT initiation is associated with worse outcomes. Adjuvant RT dose to the primary site depends on the success of the prior surgery. Patients with negative resection margins are typically treated with 50-56 Gy, whereas higher doses are recommended for those with microscopically positive resection margins (56-60 Gy) or grossly 
Merkel Cell Carcinoma, Version 1.2018

positive resection margins in cases in which further resection is not possible (60-66 Gy).

Adjuvant chemotherapy is not recommended for local disease.

\section{NCCN Recommendations for Management of the Draining Nodal Basin}

NCCN Recommendations for Clinical Node-Negative Disease: As described previously, SLNB is recommended for all patients with clinical node-negative disease who are fit for surgery.

Treatment of the nodal basin in patients with a positive SLNB should be discussed in the context of a multidisciplinary consultation. Where available, clinical trial participation is the preferred choice for patients with positive SLNB. A multidisciplinary tumor board consultation is recommended to evaluate the treatment options. Most patients should undergo completion LND and/or RT to the nodal basin. Adjuvant RT after LND is only indicated for patients with multiple involved nodes and/or the presence of extracapsular extension. Adjuvant RT after LND is generally not indicated for patients with low tumor burden on SLNB.

If SLNB results are negative, observation of the nodal basin is appropriate. Patients who are at high risk of disease progression may consider RT to the nodal basin. These include patients with profound immunosuppression and those with factors associated with increased risk of false-negative SLNB: operator or histologic failure (eg, failure to perform appropriate IHC on SLNs), anatomic features such as previous history of surgery including wide local excision, and location in the head and neck region, where risk is due to aberrant lymph node drainage and frequent presence of multiple SLN basins. Patients with immunosuppression include those with diseases such as chronic lymphocytic leukemia or HIV, and transplant recipients. Adjuvant chemotherapy is not recommended for patients with local disease.

If SLNB is not performed or is unsuccessful, RT to the nodal bed should be considered to treat subclinical disease.

NCCN Recommendations for Clinical Node-Positive Disease Confirmed by FNA or Core Biopsy: For patients with palpable lymph nodes confirmed by biopsy and imaging indicating that no distant metastases are present (M0), the panel recommends multidisciplinary tumor board consultation to consider the available treatment options for the positive lymph nodes and nodal basin. Preferences for treatment of nodal metastases vary across NCCN Member Institutions, but panel members agree that most patients should receive LND and/or primary RT. In most cases LND is the preferred approach for firstline treatment. Management of the primary tumor is the same as for patients with clinically node-negative disease.

NCCN Recommendations for Treatment after LND: Few data are available on which to base recommendations for adjuvant treatment after LND. Based on clinical practice in NCCN Member Institutions, RT is recommended after LND if extracapsular extension is detected or multiple nodes are involved. NCCN panel members are less likely to recommend adjuvant RT for patients for whom LND confirmed only a single positive lymph node without extracapsular extension. If adjuvant RT is planned after LND for multiple involved nodes and/or extracapsular extension, the recommended RT dose is 50-60 Gy.

Adjuvant systemic therapy is not routinely recommended because no survival benefit has been reported. Most NCCN Member Institutions only use systemic therapy for stage IV, distant metastatic disease (M1), with or without surgery and/or RT. A few NCCN Member Institutions suggest considering adjuvant systemic therapy for select cases of clinical (macroscopic) regional (N1b or N2) disease. However, available retrospective studies do not suggest that adjuvant chemotherapy provides survival benefit, and most institutions only use adjuvant chemotherapy for MCC in select cases.

For select patients for whom adjuvant systemic therapy is considered, treatment in the context of a clinical trial is preferred, when available. Trials testing adjuvant treatment with therapies that have been shown to be effective for unresectable and/or distant metastatic disease should be considered. ${ }^{198,199}$ Although available retrospective studies do not suggest prolonged survival benefit, if used in select patients, the panel recommends cisplatin or carboplatin with or without etoposide.

NCCN Recommendations for Adjuvant Radiation Dosing and Administration: The panel included radiation as an adjuvant treatment option for all 
stages of MCC. However, due to the lack of prospective trials with clearly defined patient cohorts and treatment protocols (eg, surgical margins prior to RT, location of radiation field), the dosing and administration recommendations are suitably broad to reflect all the approaches taken by participating NCCN Member Institutions. Ideally, adjuvant radiation is performed within 4 to 6 weeks from surgery, as delay may lead to negative outcomes; however, the NCCN recommendations do not include a specific timeframe. The panel recommends initiating RT as soon as possible after surgery.

Specifications for radiation dosing for primary and postoperative treatment of the primary site and draining lymph node basin are detailed in the algorithm under "Principles of Radiation Therapy" (see pages 750 and 751). Recommended doses depend on the extent of disease, with higher doses recommended for clinically apparent disease versus known/ suspected subclinical disease versus no evidence of disease. Irradiation of in-transit lymphatics is often not feasible unless the primary site is in close proximity to the nodal bed.

When radiation is used for definitive or adjuvant treatment of the primary tumor site, doses should generally be delivered in 2 Gy/day standard fractionation, with bolus to achieve adequate skin dose. Wide margins $(5 \mathrm{~cm})$ around the primary site should be used if possible. If electron beam is used, an energy and prescription isodose should be chosen that will deliver adequate dose to the lateral and deep margins. If RT to the primary site is being used for palliation, a less protracted fractionation schedule may be used, such as 30 Gy in 10 fractions.

\section{NCCN Recommendations for Treatment of Distant Metastatic Disease}

The panel recommends multidisciplinary tumor board consultation for patients with distant metastatic disease (M1) to consider options for management. Comprehensive imaging is recommended for all patients with any clinically detected and pathologically proven regional or distant metastases.

In general, the management of patients with distant metastases must be individually tailored. Clinical trial is preferred if available, as little data are available to suggest the best approach for active treatment. The multidisciplinary panel may consider treatment with one or more of the following modalities: systemic therapy, radiation, and surgery. Systemic therapy and RT will likely be the primary treatment options to consider. Surgery may be beneficial in highly selective circumstances for resection of oligometastasis or symptomatic lesions. All patients should receive best supportive care, and depending on the extent of the disease and other casespecific circumstances, palliative care alone may be the most appropriate option for some patients.

\section{Systemic Therapy as Active Treatment for Metastatic or Unresectable Disease}

\section{Chemotherapy}

Responses to chemotherapy in patients with MCC have been reported for a variety of regimens, including regimens that contain platinum agents (often in combination with etoposide), cyclophosphamide (often in combination with doxorubicin or epirubicin and vincristine; CAV), cyclophosphamide with methotrexate and 5-fluorouracil (CMF), paclitaxel, nab-paclitaxel, docetaxel, ifosfamide, anthracycline, 5-FU, topotecan, gemcitabine, irinotecan, and a variety of other agents. ${ }^{140,200-205}$ In analyses including more than 20 patients, reported overall response rates to chemotherapy for patients with MCC were usually around $40 \%-60 \%$, but in several studies the response rate appeared to depend on the number of prior chemotherapy regimens already attempted, with some studies reporting response rates up to $70 \%$ for first-line chemotherapy, and as low as $9 \%-20 \%$ in patients who received one or more prior lines of chemotherapy. ${ }^{140,200-206}$ Reported responses to chemotherapy were fairly short-lived, with a median duration ranging from approximately 2-9 months. ${ }^{140,201-206}$ Reported rates of toxic death in patients receiving chemotherapy for MCC were between 3\%-10\%, with elderly patients being at higher risk. ${ }^{140,201,202}$

\section{Immunotherapy}

In addition to case reports of patients with MCC responding to checkpoint immunotherapies, ${ }^{207-212}$ phase I/II trials are currently evaluating response to avelum$\mathrm{ab}$, an anti-PD-L1 agent, and to the anti-PD-1 agents pembrolizumab and nivolumab, in patients with advanced $\mathrm{MCC}$ with measurable disease. ${ }^{213-217}$ 
Merkel Cell Carcinoma, Version 1.2018

A phase II, single-arm multicenter trial (NCT02267603) tested pembrolizumab in patients with either distant metastatic $(n=24)$ or recurrent locoregional $(n=2)$ MCC not amenable to definitive surgery or RT and no prior systemic treatment for unresectable disease. ${ }^{216}$ After a median follow-up of 33 weeks (range, 7-53), the overall response rate for pembrolizumab was $56 \%$. Further follow-up is needed to assess durability of response and PFS, although based on this early analysis, response duration ranged from at least 2.2 months to at least 9.7 months. ${ }^{216}$

The JAVELIN Merkel 200 trial (NCT02155647) is an open-label multicenter trial testing avelumab in patients with histologically confirmed and measurable stage IV distant MCC. ${ }^{213-215}$ In an interim analysis of patients with no prior systemic therapy for metastatic MCC (median follow-up, 5.1 months; range, 0.3-11.3 months), overall response rate to avelumab was $62 \%$ among those with at least 3 months follow-up ( $=29)$, and confirmed response rate was $71 \%$ among those with at least 6 months follow-up. ${ }^{215}$ Further followup is needed to determine response duration, but the preliminary calculation of median PFS of 9.1 months appears promising compared with previously published retrospective analyses in which PFS after firstline chemotherapy ranged from 3 to 5 months. ${ }^{203,204}$ However, influence of chemotherapy on PFS could be negatively affected by the inherent biases of patient selection associated with retrospective studies.

The JAVELIN Merkel 200 trial also included a cohort of patients treated with avelumab after progression on one or more prior lines of systemic therapy. ${ }^{213,214}$ After a minimum 12 month follow-up (median, 16.4 months; range, 12.1-25.4), overall response rate was $33 \%$ in this cohort, and although follow-up was insufficient to determine median duration of response, an estimated $93 \%$ of responses will last at least 6 months and $74 \%$ will last at least 1 year. ${ }^{214}$ This response rate for avelumab is within the same range $(9 \%-45 \%)$ reported in retrospective studies of patients who received second- or subsequent-line chemotherapy for MCC. ${ }^{140,203-205}$ However, retrospective analyses of patients with MCC treated with secondor subsequent-line chemotherapy report short-lived responses, with median duration of response ranging from 1.7-3.4 months. ${ }^{203-205}$ For the cohort of patients in the Javelin Merkel 200 trial treated with avelumab for MCC refractory to previous lines of chemotherapy, median PFS was 2.7 months, ${ }^{214}$ which is within the same range (median 2-3 months) as reported in retrospective studies of patients receiving second-line or subsequent chemotherapy for MCC. ${ }^{203-205}$ However, the Kaplan-Meier PFS curve for avelumab appears to suggest that a notable fraction of the patients may experience long-term responses. ${ }^{214}$ Although the data need to mature, median OS was estimated to be 12.9 months for patients treated with avelumab as secondline or subsequent systemic therapy for MCC, and the Kaplan-Meier curve for OS appears to suggest that long-term survival may be possible. ${ }^{214}$ Previous retrospective studies reported median OS ranging from 4.4 to 5.7 months for patients with MCC treated with multiple lines of chemotherapy. ${ }^{203-205}$

Results from the JAVELIN Merkel 200 trial led to FDA approval of avelumab for treatment of metastatic MCC. Although the label only includes data from the cohort of patients who received avelumab for previously treated metastatic disease, the FDA approved avelumab for all patients (age 12 years or older) with metastatic MCC, regardless of treatment history. ${ }^{218}$ This indication was approved under accelerated approval based on response rate and duration of response, but continued approval may be contingent on results from confirmatory trials.

Preliminary results from the Checkmate 358 phase I/II trial that were reported in a conference abstract suggest that MCC is also sensitive to nivolumab. ${ }^{217}$ For 22 evaluable patients treated with nivolumab for MCC and measurable disease, ORR was $68 \%$ after a median follow-up of 26 weeks (range, 5-35 weeks). ${ }^{217}$ Although small sample sizes preclude meaningful statistical comparisons, ORR was slightly higher for patients without prior systemic treatment $(n=14)$ compared with those who had 1 or 2 prior systemic therapies $(n=8): 71 \%$ versus $63 \%$.

Based on the preliminary analyses of phase I/ II trials described previously, toxicity profiles in patients with MCC were similar for avelumab, pembrolizumab, and nivolumab, with treatment-related adverse event (AEs) occurring in $68 \%-77 \%$ of patients, and grade 3 or 4 in 5\%-21\%. ${ }^{213,215-217}$ Immunerelated AEs were seen in $<20 \%$ of patients receiving avelumab, and were all grade 1 or $2 .{ }^{213,215}$

\section{NCCN Recommendations for Selection of} Systemic Therapy for Distant Metastatic Disease Clinicians should exercise independent medical judgment in choosing the systemic therapy regimen. 
Although the NCCN Panel recognized that MCC is a rare disease that precludes robust randomized studies, enrollment in clinical trials is encouraged whenever available and appropriate. Clinical trials testing therapies shown to be effective against other metastatic cancers (eg, melanoma) should be considered. ${ }^{219-223}$

Preliminary data demonstrates an early promising signal for anti-PD-L1 (avelumab) and antiPD-1 (pembrolizumab, nivolumab) checkpoint immunotherapy in patients with metastatic MCC and measurable disease. Although there are no randomized comparative trials demonstrating superiority of checkpoint immunotherapy compared with chemotherapy, checkpoint immunotherapies provide response rates similar to those previously reported for chemotherapy and may provide greater durability of response. Therefore avelumab, nivolumab, and pembrolizumab are included as recommended systemic therapy options for treatment of disseminated disease, and use of cytotoxic therapies in this setting is discouraged unless the patient has contraindications to checkpoint immunotherapy or has experienced relapse or progression during or after previous treatment with checkpoint immunotherapy. Of these 3 checkpoint immunotherapies (avelumab, pembrolizumab, and nivolumab) recommended by NCCN as options for metastatic MCC, only avelumab has been FDA-approved for use in this setting. ${ }^{218,224,225}$

The safety profiles for checkpoint immunotherapies are significantly different from cytotoxic therapies, so clinician and patient education is critical for safe administration of checkpoint immunotherapies. It is important to consult the prescribing information for recommendations regarding contraindications to checkpoint immunotherapy as well as the detection and management of immune-related AEs. ${ }^{218,224,225}$

For patients with contraindications to checkpoint immunotherapy (including lack of durable response), cytotoxic therapies may be considered depending on the clinical circumstances, because these therapies are highly toxic and unlikely to offer lasting clinical benefit for patients with disseminated MCC. Due to lack of comparative trials, the literature is not directive regarding which cytotoxic therapies provide superior outcomes. However, there are data to support that MCC is chemosensitive, although the responses are not durable. For select cases, the multidisciplinary team may consider the following cytotoxic options for which at least some limited data show activity in MCC: cisplatin with or without etoposide, carboplatin with or without etoposide, topotecan, or the CAV combination therapy regimen (cyclophosphamide, doxorubicin [or epirubicin], and vincristine). There are no data regarding the optimal sequence of systemic therapies. Ongoing clinical trials are testing targeted therapies (eg, crizotinib) and other checkpoint immunotherapies in patients with MCC.

\section{Follow-up and Recurrence}

\section{Patterns of Recurrence and Metastases}

As described previously, several large studies $(n>100)$ document the development of recurrence in approximately $25 \%-50 \%$ of all cases of MCC. $5,15,18,25,26,30$ Large meta-analyses have shown that at least half of patients with MCC develop lymph node metastases and nearly one third develop distant metastases. ${ }^{23-26}$ Smaller but more recent studies have reported similar or higher rates. ${ }^{27-29}$ Based on data from large retrospective analyses $(n>100)$, the median time to recurrence in patients with MCC is about $8-9$ months, with $90 \%$ of the recurrences occurring within 24 months. ${ }^{5,30,52,129}$ Time to local recurrence is generally shorter than for regional recurrence, and time to distant metastasis is longer. ${ }^{15,18,30,178}$ Distant metastases have been shown to arise in a wide range of anatomic locations, as described in the previous section entitled "Detection of Distant Metastatic Disease" (see page 758). Due to the fast-growing nature of the disease, detection of multiple distant metastases at once is not uncommon. ${ }^{117}$

\section{Imaging Surveillance}

Retrospective studies of follow-up imaging results have reported both local and systemic MCC recurrences detected by a variety of techniques, including (but not limited to) MRI, ${ }^{117} \mathrm{CT}, 117,118,127$ and FDGPET/CT 120,125-127,129,133,134,137 Data on the accuracy of different imaging techniques for follow-up surveillance is limited, because very few of these studies report whether or not the follow-up imaging findings were histologically confirmed. ${ }^{118,125,126}$ The yield from different imaging follow-up regimens and techniques is also unknown, as the available retrospective studies that evaluated imaging results did not clarify the frequency of follow-up surveillance or whether the 
patients were believed to have no evidence of disease prior to follow-up imaging. One retrospective study of 53 scans in 36 patients reported that FDG-PET or FDG-PET/CT results had a high impact on management plans in $45 \%$ of patients when used for "restaging or surveillance," defined as scans taken more than 7 months after definitive treatment to assess suspected relapse or ongoing response. ${ }^{134}$

\section{Risk of Developing Secondary Cancers During Follow-up}

As will be described in the section entitled "Presence of Secondary Malignancy" in the next update of the complete version of the NCCN Guidelines for MCC (to be posted at NCCN.org), patients who have had $\mathrm{MCC}$ are at increased risk for a second primary malignancy-either another primary MCC, a different skin cancer, or other types of noncutaneous malignancies. 32,226-229 Large retrospective analyses have found that $9 \%-19 \%$ of patients diagnosed with MCC subsequently develop another malignancy. 3,226-229

\section{NCCN Recommendations for Follow-up}

The NCCN Panel recommends close clinical followup for patients with MCC starting immediately after diagnosis and treatment. The physical examination should include a complete skin and complete lymph node examination every 3 to 6 months for the first 3 years, then every 6 to 12 months thereafter. The recommended frequency of follow-up visits is purposely broad to allow for an individualized schedule based on the risk of recurrence, stage of disease, and other factors such as patient anxiety and clinician preference. The panel's recommendations for frequent clinical exams during the first 3 years also reflect the fact that MCC will recur in up to half of patients, and most recurrences occur within the first few years

\section{References}

1. Paulson KG, Park SY, Vandeven NA, et al. Merkel cell carcinoma: current US incidence and projected increases based on changing demographics. J Am Acad Dermatol 2018;78:457-463 e452.

2. Hodgson NC. Merkel cell carcinoma: changing incidence trends. J Surg Oncol 2005;89:1-4.

3. Reichgelt BA, Visser O. Epidemiology and survival of Merkel cell carcinoma in the Netherlands. a population-based study of 808 cases in 1993-2007. Eur J Cancer 2011;47:579-585.

4. Lyhne D, Lock-Andersen J, Dahlstrom K, et al. Rising incidence of Merkel cell carcinoma. J Plast Surg Hand Surg 2011;45:274-280.

5. Santamaria-Barria JA, Boland GM, Yeap BY, et al. Merkel cell carcinoma: 30-year experience from a single institution. Ann Surg Oncol 2013;20:1365-1373. after diagnosis. Education regarding self-examination of the skin is useful for patients with MCC because of their increased risk for other non-melanoma skin cancers.

Imaging studies should be performed as clinically indicated, such as in cases of emergent adenopathy or organomegaly, unexplained changes in liver function tests, or development of new suspicious symptoms. For high-risk patients (eg, stage IIIB or higher, immunosuppression), routine imaging should be considered. Recommended imaging modality options are the same as for the initial clinical workup in patients in whom regional or distant metastases are suspected: brain MRI with contrast and neck/chest/ abdomen/pelvis CT with contrast or whole body FDG-PET/CT. Whole body FDG-PET/CT scans may be useful to identify and quantify metastases, especially bone involvement. If whole body FDG-PET/ CT is not available, CT or MRI with contrast may be used. As immunosuppressed patients are at high risk for recurrence, more frequent follow-up may be indicated. To lower the risk of recurrence/progression, immunosuppressive treatments should be minimized as clinically feasible.

As described in the section entitled "MCPyV" (see page 754), MCPyV oncoprotein antibody testing performed at initial work up may help guide surveillance. ${ }^{57-60}$ Patients who are oncoprotein antibody seronegative at diagnosis may be at higher risk of recurrence and may benefit from more intensive surveillance. ${ }^{57}$ For patients who are seropositive at baseline, the MCPyV oncoprotein antibody test may be a useful component of ongoing surveillance because a rising titer can be an early indicator of recurrence. ${ }^{57}$

For discussion of treatment of recurrence, see the complete NCCN Guidelines for MCC recommendations online at NCCN.org.

6. Youlden DR, Soyer HP, Youl PH, et al. Incidence and survival for Merke cell carcinoma in Queensland, Australia, 1993-2010. JAMA Dermatol 2014;150:864-872.

7. Fitzgerald TL, Dennis S, Kachare SD, et al. Dramatic increase in the incidence and mortality from Merkel cell carcinoma in the United States. Am Surg 2015;81:802-806

8. Goon PK, Greenberg DC, Igali L, Levell NJ. Merkel cell carcinoma: rising incidence in the east of England. J Eur Acad Dermatol Venereol 2016;30:2052-2055.

9. Rubio-Casadevall J, Hernandez-Pujol AM, Ferreira-Santos MC, et al Trends in incidence and survival analysis in non-melanoma skin cancer from 1994 to 2012 in Girona, Spain: a population-based study. Cancer Epidemiol 2016;45:6-10.

10. Zaar $\mathrm{O}$, Gillstedt $\mathrm{M}$, Lindelof $\mathrm{B}$, et al. Merkel cell carcinoma incidence is increasing in Sweden. J Eur Acad Dermatol Venereol 2016. 
11. Lemos B, Nghiem P. Merkel cell carcinoma: more deaths but still no pathway to blame. J Invest Dermatol 2007;127:2100-2103.

12. Eftekhari F, Wallace S, Silva EG, Lenzi R. Merkel cell carcinoma of the skin: imaging and clinical features in 93 cases. Br J Radiol 1996;69:226233.

13. Walsh NM. Primary neuroendocrine (Merkel cell) carcinoma of the skin: morphologic diversity and implications thereof. Hum Pathol 2001;32:680689.

14. Heath M, Jaimes N, Lemos B, et al. Clinical characteristics of Merkel cell carcinoma at diagnosis in 195 patients: the AEIOU features. J Am Acad Dermatol 2008;58:375-381.

15. Tarantola TI, Vallow LA, Halyard MY, et al. Prognostic factors in Merkel cell carcinoma: analysis of 240 cases. J Am Acad Dermatol 2013;68:425432.

16. Suarez AL, Louis P, Kitts J, et al. Clinical and dermoscopic features of combined cutaneous squamous cell carcinoma (SCC)/neuroendocrine [Merkel cell] carcinoma (MCC). J Am Acad Dermatol 2015;73:968-975.

17. Agelli M, Clegg LX. Epidemiology of primary Merkel cell carcinoma in the United States. J Am Acad Dermatol 2003;49:832-841.

18. Hitchcock CL, Bland KI, Laney RG, 3rd, et al. Neuroendocrine (Merkel cell) carcinoma of the skin. Its natural history, diagnosis, and treatment. Ann Surg 1988;207:201-207.

19. Lemos BD, Storer BE, Iyer JG, et al. Pathologic nodal evaluation improves prognostic accuracy in Merkel cell carcinoma: analysis of 5823 cases as the basis of the first consensus staging system. J Am Acad Dermatol 2010;63:751-761

20. Albores-Saavedra J, Batich K, Chable-Montero F, et al. Merkel cell carcinoma demographics, morphology, and survival based on 3870 cases: a population based study. J Cutan Pathol 2010;37:20-27.

21. Harms KL, Healy MA, Nghiem P, et al. Analysis of prognostic factors from 9387 Merkel cell carcinoma cases forms the basis for the new 8th edition AJCC Staging System. Ann Surg Oncol 2016;23:3564-3571.

22. Sridharan V, Muralidhar V, Margalit DN, et al. Merkel cell carcinoma: a population analysis on survival. J Natl Compr Canc Netw 2016;14:12471257.

23. Mercer D, Brander P, Liddell $\mathrm{K}$. Merkel cell carcinoma: the clinical course. Ann Plast Surg 1990;25:136-141.

24. Pitale M, Sessions RB, Husain S. An analysis of prognostic factors in cutaneous neuroendocrine carcinoma. Laryngoscope 1992;102:244-249.

25. Akhtar S, Oza KK, Wright J. Merkel cell carcinoma: report of 10 cases and review of the literature. J Am Acad Dermatol 2000;43:755-767.

26. Medina-Franco H, Urist MM, Fiveash J, et al. Multimodality treatment of Merkel cell carcinoma: case series and literature review of 1024 cases. Ann Surg Oncol 2001;8:204-208.

27. McAfee WJ, Morris CG, Mendenhall CM, et al. Merkel cell carcinoma treatment and outcomes. Cancer 2005;104:1761-1764.

28. Guler-Nizam E, Leiter $U$, Metzler G, et al. Clinical course and prognostic factors of Merkel cell carcinoma of the skin. Br J Dermatol 2009;161:9094.

29. Lim CS, Whalley D, Haydu LE, et al. Increasing tumor thickness is associated with recurrence and poorer survival in patients with Merkel cell carcinoma. Ann Surg Oncol 2012;19:3325-3334.

30. Allen PJ, Bowne WB, Jaques DP, et al. Merkel cell carcinoma: prognosis and treatment of patients from a single institution. J Clin Oncol 2005;23:2300-2309.

31. Harrington $\mathrm{C}, \mathrm{Kwan}$ W. Radiotherapy and conservative surgery in the locoregional management of Merkel cell carcinoma: the British Columbia Cancer Agency experience. Ann Surg Oncol 2016;23:573-578.

32. Kaae J, Hansen AV, Biggar RJ, et al. Merkel cell carcinoma: incidence, mortality, and risk of other cancers. J Natl Cancer Inst 2010;102:793-801.

33. Asgari MM, Sokil MM, Warton EM, et al. Effect of host, tumor, diagnostic, and treatment variables on outcomes in a large cohort with Merkel cell carcinoma. JAMA Dermatol 2014;150:716-723.

34. Fields RC, Busam KJ, Chou JF, et al. Five hundred patients with Merkel cell carcinoma evaluated at a single institution. Ann Surg 2011;254:465-475.

35. Miller RW, Rabkin CS. Merkel cell carcinoma and melanoma: etiological similarities and differences. Cancer Epidemiol Biomarkers Prev 1999;8:153-158.

36. Lanoy E, Costagliola D, Engels EA. Skin cancers associated with HIV infection and solid-organ transplantation among elderly adults. Int J Cancer 2010;126:1724-1731.
37. Lunder EJ, Stern RS. Merkel-cell carcinomas in patients treated with methoxsalen and ultraviolet A radiation. N Engl J Med 1998;339:12471248 .

38. Smith FO, Yue B, Marzban SS, et al. Both tumor depth and diameter are predictive of sentinel lymph node status and survival in Merkel cell carcinoma. Cancer 2015;121:3252-3260.

39. Ezaldein HH, Ventura A, DeRuyter NP, et al. Understanding the influence of patient demographics on disease severity, treatment strategy, and survival outcomes in merkel cell carcinoma: a surveillance, epidemiology, and end-results study. Oncoscience 2017;4:106-114.

40. Heenan PJ, Cole JM, Spagnolo DV. Primary cutaneous neuroendocrine carcinoma (Merkel cell tumor). An adnexal epithelial neoplasm. Am J Dermatopathol 1990;12:7-16

41. Higaki-Mori H, Kuwamoto S, Iwasaki T, et al. Association of Merkel cell polyomavirus infection with clinicopathological differences in Merkel cell carcinoma. Hum Pathol 2012;43:2282-2291.

42. Lai JH, Fleming KE, Ly TY, et al. Pure versus combined Merkel cell carcinomas: immunohistochemical evaluation of cellular proteins ( $\mathrm{p} 53$, $\mathrm{Bcl}-2$, and c-kit) reveals significant overexpression of $\mathrm{p} 53$ in combined tumors. Hum Pathol 2015;46:1290-1296.

43. Harms PW, Vats P, Verhaegen ME, et al. The distinctive mutational spectra of polyomavirus-negative Merkel cell carcinoma. Cancer Res 2015;75:3720-3727.

44. Wong SQ, Waldeck K, Vergara IA, et al. UV-associated mutations underlie the etiology of MCV-negative Merkel cell carcinomas. Cancer Res 2015;75:5228-5234.

45. Goh G, Walradt T, Markarov V, et al. Mutational landscape of MCPyVpositive and MCPyV-negative Merkel cell carcinomas with implications for immunotherapy. Oncotarget 2016;7:3403-3415.

46. Engels EA, Frisch M, Goedert JJ, et al. Merkel cell carcinoma and HIV infection. Lancet 2002;359:497-498.

47. Koljonen $\mathrm{V}$, Kukko $\mathrm{H}$, Tukiainen $\mathrm{E}$, et al. Incidence of Merkel cell carcinoma in renal transplant recipients. Nephrol Dial Transplant 2009;24:3231-3235.

48. Koljonen V, Kukko H, Pukkala E, et al. Chronic lymphocytic leukaemia patients have a high risk of Merkel-cell polyomavirus DNA-positive Merkel-cell carcinoma. Br J Cancer 2009;101:1444-1447.

49. Koljonen V, Sahi H, Bohling T, Makisalo H. Post-transplant Merkel cell carcinoma. Acta Derm Venereol 2016;96:442-447.

50. Paulson KG, Iyer JG, Blom A, et al. Systemic immune suppression predicts diminished Merkel cell carcinoma-specific survival independent of stage. J Invest Dermatol 2013;133:642-646.

51. Liang E, Brower JV, Rice SR, et al. Merkel cell carcinoma analysis of outcomes: a 30-year experience. PLoS One 2015;10:e0129476.

52. Hui AC, Stillie AL, Seel M, Ainslie J. Merkel cell carcinoma: 27-year experience at the Peter MacCallum Cancer Centre. Int J Radiat Oncol Biol Phys 2011;80:1430-1435.

53. Feng H, Shuda M, Chang Y, Moore PS. Clonal integration of a polyomavirus in human Merkel cell carcinoma. Science 2008;319:1096-1100.

54. Rollison DE, Giuliano AR, Becker JC. New virus associated with merkel cell carcinoma development. J Natl Compr Canc Netw 2010;8:874-880.

55. Batinica M, Akgul B, Silling S, et al. Correlation of Merkel cell polyomavirus positivity with PDGFRalpha mutations and survivin expression in Merkel cell carcinoma. J Dermatol Sci 2015;79:43-49.

56. Santos-Juanes J, Fernandez-Vega I, Fuentes N, et al. Merkel cell carcinoma and Merkel cell polyomavirus: a systematic review and meta-analysis. Br J Dermatol 2015;173:42-49.

57. Paulson KG, Lewis CW, Redman MW, et al. Viral oncoprotein antibodies as a marker for recurrence of Merkel cell carcinoma: a prospective validation study. Cancer 2017;123:1464-1474.

58. Paulson KG, Carter JJ, Johnson LG, et al. Antibodies to merkel cell polyomavirus $\mathrm{T}$ antigen oncoproteins reflect tumor burden in merkel cell carcinoma patients. Cancer Res 2010;70:8388-8397.

59. Samimi M, Molet L, Fleury M, et al. Prognostic value of antibodies to Merkel cell polyomavirus $\mathrm{T}$ antigens and VP1 protein in patients with Merkel cell carcinoma. Br J Dermatol 2016;174:813-822.

60. Touze A, Le Bidre E, Laude H, et al. High levels of antibodies against merkel cell polyomavirus identify a subset of patients with merkel cell carcinoma with better clinical outcome. J Clin Oncol 2011;29:1612-1619.

61. Goepfert H, Remmler D, Silva E, Wheeler B. Merkel cell carcinoma (endocrine carcinoma of the skin) of the head and neck. Arch Otolaryngol 1984;110:707-712. 
62. Ball NJ, Tanhuanco-Kho G. Merkel cell carcinoma frequently shows histologic features of basal cell carcinoma: a study of 30 cases. J Cutan Pathol 2007;34:612-619.

63. Frigerio B, Capella C, Eusebi V, et al. Merkel cell carcinoma of the skin: the structure and origin of normal Merkel cells. Histopathology 1983; 7:229-249

64. Gu J, Polak JM, Van Noorden S, et al. Immunostaining of neuron-specific enolase as a diagnostic tool for Merkel cell tumors. Cancer 1983;52:1039_ 1043.

65. Skelton HG, Smith KJ, Hitchcock CL, et al. Merkel cell carcinoma: analysis of clinical, histologic, and immunohistologic features of 132 cases with relation to survival. J Am Acad Dermatol 1997;37:734-739.

66. Llombart B, Monteagudo C, Lopez-Guerrero JA, et al. Clinicopathological and immunohistochemical analysis of 20 cases of Merkel cell carcinoma in search of prognostic markers. Histopathology 2005;46:622-634.

67. Anderson SE, Beer KT, Banic A, et al. MRI of merkel cell carcinoma: histologic correlation and review of the literature. AJR Am J Roentgenol 2005;185:1441-1448.

68. Gollard R, Weber R, Kosty MP, et al. Merkel cell carcinoma: review of 22 cases with surgical, pathologic, and therapeutic considerations. Cancer 2000;88:1842-1851.

69. Hall BJ, Pincus LB, Yu SS, et al. Immunohistochemical prognostication of Merkel cell carcinoma: p63 expression but not polyomavirus status correlates with outcome. J Cutan Pathol 2012;39:911-917.

70. Henderson SA, Tetzlaff MT, Pattanaprichakul P, et al. Detection of mitotic figures and G2 + tumor nuclei with histone markers correlates with worse overall survival in patients with Merkel cell carcinoma. J Cutan Pathol 2014;41:846-852.

71. Warner TF, Uno $\mathrm{H}, \mathrm{Hafez}$ GR, et al. Merkel cells and Merkel cell tumors. Ultrastructure, immunocytochemistry and review of the literature. Cancer 1983;52:238-245.

72. Johansson L, Tennvall J, Akerman M. Immunohistochemical examination of 25 cases of Merkel cell carcinoma: a comparison with small cell carcinoma of the lung and oesophagus, and a review of the literature. APMIS 1990;98:741-752.

73. Haag ML, Glass LF, Fenske NA. Merkel cell carcinoma: diagnosis and treatment. Dermatol Surg 1995;21:669-683.

74. Schmidt U, Muller U, Metz KA, Leder LD. Cytokeratin and neurofilament protein staining in Merkel cell carcinoma of the small cell type and small cell carcinoma of the lung. Am J Dermatopathol 1998;20:346-351.

75. Bobos M, Hytiroglou $\mathrm{P}$, Kostopoulos I, et al. Immunohistochemical distinction between merkel cell carcinoma and small cell carcinoma of the lung. Am J Dermatopathol 2006;28:99-104.

76. Kolhe R, Reid MD, Lee JR, et al. Immunohistochemical expression of PAX5 and TdT by Merkel cell carcinoma and pulmonary small cell carcinoma: a potential diagnostic pitfall but useful discriminatory marker. Int J Clin Exp Pathol 2013;6:142-147.

77. Moll R, Lowe A, Laufer J, Franke WW. Cytokeratin 20 in human carcinomas: a new histodiagnostic marker detected by monoclonal antibodies. Am J Pathol 1992;140:427-447.

78. Miettinen M. Keratin 20 : immunohistochemical marker for gastrointestinal, urothelial, and Merkel cell carcinomas. Mod Pathol 1995;8:384-388.

79. Chan JK, Suster S, Wenig BM, et al. Cytokeratin 20 immunoreactivity distinguishes Merkel cell (primary cutaneous neuroendocrine) carcinomas and salivary gland small cell carcinomas from small cell carcinomas of various sites. Am J Surg Pathol 1997;21:226-234.

80. Scott MP, Helm KF. Cytokeratin 20: a marker for diagnosing Merkel cell carcinoma. Am J Dermatopathol 1999;21:16-20.

81. Byrd-Gloster AL, Khoor A, Glass LF, et al. Differential expression of thyroid transcription factor 1 in small cell lung carcinoma and Merkel cell tumor. Hum Pathol 2000;31:58-62.

82. Hanly AJ, Elgart GW, Jorda M, et al. Analysis of thyroid transcription factor- 1 and cytokeratin 20 separates merkel cell carcinoma from small cell carcinoma of lung. J Cutan Pathol 2000;27:118-120.

83. Ordonez NG. Value of thyroid transcription factor-1 immunostaining in distinguishing small cell lung carcinomas from other small cell carcinomas. Am J Surg Pathol 2000;24:1217-1223.

84. Cheuk W, Kwan MY, Suster S, Chan JK. Immunostaining for thyroid transcription factor 1 and cytokeratin 20 aids the distinction of small cell carcinoma from Merkel cell carcinoma, but not pulmonary from extrapulmonary small cell carcinomas. Arch Pathol Lab Med 2001;125:228-231

85. Leech SN, Kolar AJ, Barrett PD, et al. Merkel cell carcinoma can be distinguished from metastatic small cell carcinoma using antibodies to cytokeratin 20 and thyroid transcription factor 1. J Clin Pathol 2001;54:727-729.

86. Busam KJ, Jungbluth AA, Rekthman N, et al. Merkel cell polyomavirus expression in merkel cell carcinomas and its absence in combined tumors and pulmonary neuroendocrine carcinomas. Am J Surg Pathol 2009;33:1378-1385.

87. Jensen K, Kohler S, Rouse RV. Cytokeratin staining in Merkel cell carcinoma: an immunohistochemical study of cytokeratins $5 / 6,7,17$, and 20. Appl Immunohistochem Mol Morphol 2000;8:310-315.

88. Asioli S, Righi A, de Biase D, et al. Expression of p63 is the sole independent marker of aggressiveness in localised (stage I-II) Merkel cell carcinomas. Mod Pathol 2011;24:1451-1461.

89. Kim J, McNiff JM. Nuclear expression of survivin portends a poor prognosis in Merkel cell carcinoma. Mod Pathol 2008;21:764-769.

90. Acebo E, Vidaurrazaga N, Varas C, et al. Merkel cell carcinoma: a clinicopathological study of 11 cases. J Eur Acad Dermatol Venereol 2005;19:546-551.

91. Sidiropoulos M, Hanna W, Raphael SJ, Ghorab Z. Expression of TdT in Merkel cell carcinoma and small cell lung carcinoma. Am J Clin Pathol 2011;135:831-838.

92. Marghalani S, Feller JK, Mahalingam M, Mirzabeigi M. Huntingtin interacting protein 1 as a histopathologic adjunct in the diagnosis of Merkel cell carcinoma. Int J Dermatol 2015;54:640-647.

93. Sibley RK, Dahl D. Primary neuroendocrine (Merkel cell?) carcinoma of the skin. II. An immunocytochemical study of 21 cases. Am J Surg Pathol 1985;9:109-116.

94. Visscher D, Cooper PH, Zarbo RJ, Crissman JD. Cutaneous neuroendocrine (Merkel cell) carcinoma: an immunophenotypic, clinicopathologic, and flow cytometric study. Mod Pathol 1989;2:331-338.

95. Shah IA, Netto D, Schlageter MO, et al. Neurofilament immunoreactivity in Merkel-cell tumors: a differentiating feature from small-cell carcinoma. Mod Pathol 1993;6:3-9.

96. Koljonen V, Haglund C, Tukiainen E, Bohling T. Neuroendocrine differentiation in primary Merkel cell carcinoma--possible prognostic significance. Anticancer Res 2005;25:853-858.

97. Knopf A, Bas M, Hofauer B, et al. Clinicopathological characteristics of head and neck Merkel cell carcinomas. Head Neck 2017;39:92-97.

98. Leong AS, Phillips GE, Pieterse AS, Milios J. Criteria for the diagnosis of primary endocrine carcinoma of the skin (Merkel cell carcinoma). A histological, immunohistochemical and ultrastructural study of 13 cases. Pathology 1986;18:393-399.

99. Gould VE, Wiedenmann B, Lee I, et al. Synaptophysin expression in neuroendocrine neoplasms as determined by immunocytochemistry. Am J Pathol 1987;126:243-257.

100. Panse G, McNiff JM, Ko CJ. Basal cell carcinoma: CD56 and cytokeratin $5 / 6$ staining patterns in the differential diagnosis with Merkel cell carcinoma. J Cutan Pathol 2017;44:553-556.

101. Smith KJ, Skelton HG, 3rd, Holland TT, et al. Neuroendocrine (Merkel cell) carcinoma with an intraepidermal component. Am J Dermatopathol 1993;15:528-533.

102. Saeb-Lima M, Montante-Montes de Oca D, Albores-Saavedra J. Merkel cell carcinoma with eccrine differentiation: a clinicopathologic study of 7 cases. Ann Diagn Pathol 2008;12:410-414.

103. Martin B, Poblet E, Rios JJ, et al. Merkel cell carcinoma with divergent differentiation: histopathological and immunohistochemical study of 15 cases with PCR analysis for Merkel cell polyomavirus. Histopathology 2013;62:711-722

104. D'Agostino M, Cinelli C, Willard R, et al. Epidermotropic Merkel cell carcinoma: a case series with histopathologic examination. J Am Acad Dermatol 2010;62:463-468.

105. Miner AG, Patel RM, Wilson DA, et al. Cytokeratin 20-negative Merkel cell carcinoma is infrequently associated with the Merkel cell polyomavirus. Mod Pathol 2015;28:498-504.

106. Pulitzer MP, Brannon AR, Berger MF, et al. Cutaneous squamous and neuroendocrine carcinoma: genetically and immunohistochemically different from Merkel cell carcinoma. Mod Pathol 2015;28:1023-1032.

107. Mott RT, Smoller BR, Morgan MB. Merkel cell carcinoma: a clinicopathologic study with prognostic implications. J Cutan Pathol 2004;31:217-223

108. Kukko HM, Koljonen VS, Tukiainen EJ, et al. Vascular invasion is an early event in pathogenesis of Merkel cell carcinoma. Mod Pathol 2010;23:1151-1156. 
109. Sihto H, Kukko H, Koljonen V, et al. Merkel cell polyomavirus infection, large $\mathrm{T}$ antigen, retinoblastoma protein and outcome in Merkel cell carcinoma. Clin Cancer Res 2011;17:4806-4813.

110. Zaragoza J, Kervarrec T, Touze A, et al. A high neutrophil-to-lymphocyte ratio as a potential marker of mortality in patients with Merkel cell carcinoma: a retrospective study. J Am Acad Dermatol 2016;75:712-721 e711.

111. Schrama D, Peitsch WK, Zapatka M, et al. Merkel cell polyomavirus status is not associated with clinical course of Merkel cell carcinoma. J Invest Dermatol 2011;131:1631-1638.

112. Amin MB, Edge S, Greene F, et al., eds. AJCC Cancer Staging Manual (ed 8th). New York: Springer International Publishing; 2017.

113. Rao $\mathrm{P}$, Balzer BL, Lemos BD, et al. Protocol for the examination of specimens from patients with merkel cell carcinoma of the skin. Arch Pathol Lab Med 2010;134:341-344.

114. Smoller BR, Bichakjian CK, Brown JA, et al. Protocol for the examination of specimens from patients with Merkel cell carcinoma of the skin, version 4.0.0.1. College of American Pathologists Cancer Protocol Templates 2017. Available at: https://www.doc-txt.net/College-of-AmericanPathologists-Cancer-Protocols.pdf. Accessed May 29, 2018.

115. Bhatia S, Storer BE, Iyer JG, et al. Adjuvant radiation therapy and chemotherapy in Merkel cell carcinoma: survival analyses of 6908 cases from the National Cancer Data Base. J Natl Cancer Inst 2016;108.

116. Smith VA, Camp ER, Lentsch EJ. Merkel cell carcinoma: identification of prognostic factors unique to tumors located in the head and neck based on analysis of SEER data. Laryngoscope 2012;122:1283-1290.

117. Kouzmina M, Koljonen V, Leikola J, et al. Frequency and locations of systemic metastases in Merkel cell carcinoma by imaging. Acta Radiol Open 2017;6:2058460117700449.

118. Gollub MJ, Gruen DR, Dershaw DD. Merkel cell carcinoma: CT findings in 12 patients. AJR Am J Roentgenol 1996;167:617-620.

119. Gupta SG, Wang LC, Penas PF, et al. Sentinel lymph node biopsy for evaluation and treatment of patients with Merkel cell carcinoma: the Dana-Farber experience and meta-analysis of the literature. Arch Dermatol 2006;142:685-690.

120. Peloschek P, Novotny C, Mueller-Mang C, et al. Diagnostic imaging in Merkel cell carcinoma: lessons to learn from 16 cases with correlation of sonography, CT, MRI and PET. Eur J Radiol 2010;73:317-323.

121. Colgan MB, Tarantola TI, Weaver AL, et al. The predictive value of imaging studies in evaluating regional lymph node involvement in Merkel cell carcinoma. J Am Acad Dermatol 2012;67:1250-1256.

122. Kwekkeboom DJ, Hoff AM, Lamberts SW, et al. Somatostatin analogue scintigraphy. A simple and sensitive method for the in vivo visualization of Merkel cell tumors and their metastases. Arch Dermatol 1992;128:818821.

123. Guitera-Rovel P, Lumbroso J, Gautier-Gougis MS, et al. Indium-111 octreotide scintigraphy of Merkel cell carcinomas and their metastases. Ann Oncol 2001;12:807-811.

124. Durani BK, Klein A, Henze $M$, et al. Somatostatin analogue scintigraphy in Merkel cell tumours. Br J Dermatol 2003;148:1135-1140.

125. Belhocine T, Pierard GE, Fruhling J, et al. Clinical added-value of 18FDGPET in neuroendocrine-merkel cell carcinoma. Oncol Rep 2006;16:347352.

126. Concannon R, Larcos GS, Veness M. The impact of (18)F-FDG-PETCT scanning for staging and management of Merkel cell carcinoma: results from Westmead Hospital, Sydney, Australia. J Am Acad Dermatol 2010;62:76-84

127. Maury G, Dereure $O$, Du-Thanh A, et al. Interest of (18)F-FDG-PETCT scanning for staging and management of merkel cell carcinoma: a retrospective study of 15 patients. J Eur Acad Dermatol Venereol 2011;25:1420-1427.

128. Siva S, Byrne K, Seel M, et al. 18F-FDG-PET provides high-impact and powerful prognostic stratification in the staging of Merkel cell carcinoma: a 15-year institutional experience. J Nucl Med 2013;54:1223-1229.

129. Hawryluk EB, O'Regan KN, Sheehy N, et al. Positron emission tomography/computed tomography imaging in Merkel cell carcinoma: a study of 270 scans in 97 patients at the Dana-Farber/Brigham and Women's Cancer Center. J Am Acad Dermatol 2013;68:592-599.

130. Ibrahim SF, Ahronowitz I, McCalmont TH, et al. 18F-fluorodeoxyglucose positron emission tomography-computed tomography imaging in the management of Merkel cell carcinoma: a single-institution retrospective study. Dermatol Surg 2013;39:1323-1333.

131. Treglia G, Kakhki VR, Giovanella L, Sadeghi R. Diagnostic performance of fluorine-18-fluorodeoxyglucose positron emission tomography in patients with Merkel cell carcinoma: a systematic review and meta-analysis. Am J Clin Dermatol 2013;14:437-447.

132. Buder K, Lapa C, Kreissl MC, et al. Somatostatin receptor expression in Merkel cell carcinoma as target for molecular imaging. BMC Cancer 2014;14:268.

133. George A, Girault S, Testard A, et al. The impact of (18)F-FDG-PET/CT on Merkel cell carcinoma management: a retrospective study of 66 scans from a single institution. Nucl Med Commun 2014;35:282-290.

134. Byrne K, Siva S, Chait L, et al. 15-Year experience of 18F-FDG-PET imaging in response assessment and restaging after definitive treatment of Merkel cell carcinoma. J Nucl Med 2015;56:1328-1333.

135. Liu J, Larcos G, Howle J, Veness M. Lack of clinical impact of (18) F-fluorodeoxyglucose positron emission tomography with simultaneous computed tomography for stage I and II Merkel cell carcinoma with concurrent sentinel lymph node biopsy staging: a single institutional experience from Westmead Hospital, Sydney. Australas J Dermatol 2017;58:99-105.

136. Sollini M, Taralli S, Milella M, et al. Somatostatin receptor positron emission tomography/computed tomography imaging in Merkel cell carcinoma. J Eur Acad Dermatol Venereol 2016;30:1507-1511.

137. Ben-Haim S, Garkaby J, Primashvili N, et al. Metabolic assessment of Merkel cell carcinoma: the role of 18F-FDG-PET/CT. Nucl Med Commun 2016;37:865-873.

138. Poulsen M, Macfarlane D, Veness M, et al. Prospective analysis of the utility of 18-FDG-PET in Merkel cell carcinoma of the skin: a Trans Tasman Radiation Oncology Group study, TROG 09:03. J Med Imaging Radiat Oncol 2018.

139. Pilotti S, Rilke F, Bartoli C, Grisotti A. Clinicopathologic correlations of cutaneous neuroendocrine Merkel cell carcinoma. J Clin Oncol 1988;6:1863-1873.

140. Voog E, Biron P, Martin JP, Blay JY. Chemotherapy for patients with locally advanced or metastatic Merkel cell carcinoma. Cancer 1999;85:25892595.

141. Fields RC, Busam KJ, Chou JF, et al. Recurrence after complete resection and selective use of adjuvant therapy for stage I through III Merkel cell carcinoma. Cancer 2012;118:3311-3320.

142. Schneider S, Thurnher D, Erovic BM. Merkel cell carcinoma: interdisciplinary management of a rare disease. J Skin Cancer 2013;2013:189342.

143. Foote M, Veness M, Zarate D, Poulsen M. Merkel cell carcinoma: the prognostic implications of an occult primary in stage IIIB (nodal) disease. J Am Acad Dermatol 2012;67:395-399.

144. Tarantola TI, Vallow LA, Halyard MY, et al. Unknown primary Merkel cell carcinoma: 23 new cases and a review. J Am Acad Dermatol 2013;68:433440.

145. Chen KT, Papavasiliou P, Edwards K, et al. A better prognosis for Merkel cell carcinoma of unknown primary origin. Am J Surg 2013;206:752-757.

146. Mehrany K, Otley CC, Weenig RH, et al. A meta-analysis of the prognostic significance of sentinel lymph node status in Merkel cell carcinoma. Dermatol Surg 2002;28:113-117; discussion 117.

147. Schwartz JL, Bichakjian CK, Lowe L, et al. Clinicopathologic features of primary Merkel cell carcinoma: a detailed descriptive analysis of a large contemporary cohort. Dermatol Surg 2013;39:1009-1016.

148. Gunaratne DA, Howle JR, Veness MJ. Sentinel lymph node biopsy in Merkel cell carcinoma: a 15-year institutional experience and statistical analysis of 721 reported cases. Br J Dermatol 2016;174:273-281.

149. Jouary T, Kubica E, Dalle $S$, et al. Sentinel node status and immunosuppression: recurrence factors in localized Merkel cell carcinoma. Acta Derm Venereol 2015;95:835-840.

150. Sims JR, Grotz TE, Pockaj BA, et al. Sentinel lymph node biopsy in Merkel cell carcinoma: the Mayo Clinic experience of 150 patients. Surg Oncol 2018;27:11-17.

151. Fields RC, Busam KJ, Chou JF, et al. Recurrence and survival in patients undergoing sentinel lymph node biopsy for merkel cell carcinoma: analysis of 153 patients from a single institution. Ann Surg Oncol 2011;18:2529_ 2537.

152. Schwartz JL, Griffith KA, Lowe L, et al. Features predicting sentinel lymph node positivity in Merkel cell carcinoma. J Clin Oncol 2011;29:10361041.

153. Feldmeyer L, Hudgens CW, Ray-Lyons G, et al. Density, distribution, and composition of immune infiltrates correlate with survival in Merkel cell carcinoma. Clin Cancer Res 2016;22:5553-5563. 
154. Servy A, Maubec E, Sugier PE, et al. Merkel cell carcinoma: value of sentinel lymph-node status and adjuvant radiation therapy. Ann Oncol 2016;27:914-919.

155. Kachare SD, Wong JH, Vohra NA, et al. Sentinel lymph node biopsy is associated with improved survival in Merkel cell carcinoma. Ann Surg Oncol 2014;21:1624-1630.

156. Soult MC, Feliberti EC, Silverberg ML, Perry RR. Merkel cell carcinoma: high recurrence rate despite aggressive treatment. J Surg Res 2012;177:7580 .

157. Sattler E, Geimer T, Sick I, et al. Sentinel lymph node in Merkel cell carcinoma: to biopsy or not to biopsy? J Dermatol 2013;40:374-379.

158. Allen PJ, Busam K, Hill AD, et al. Immunohistochemical analysis of sentinel lymph nodes from patients with Merkel cell carcinoma. Cancer 2001;92:1650-1655.

159. Su LD, Lowe L, Bradford CR, et al. Immunostaining for cytokeratin 20 improves detection of micrometastatic Merkel cell carcinoma in sentinel lymph nodes. J Am Acad Dermatol 2002;46:661-666.

160. Schmalbach CE, Lowe L, Teknos TN, et al. Reliability of sentinel lymph node biopsy for regional staging of head and neck Merkel cell carcinoma. Arch Otolaryngol Head Neck Surg 2005;131:610-614.

161. Maza S, Trefzer U, Hofmann M, et al. Impact of sentinel lymph node biopsy in patients with Merkel cell carcinoma: results of a prospective study and review of the literature. Eur J Nucl Med Mol Imaging 2006;33:433-440.

162. Loyo M, Schussel J, Colantuoni E, et al. Detection of Merkel cell virus and correlation with histologic presence of Merkel cell carcinoma in sentinel lymph nodes. Br J Cancer 2012;106:1314-1319.

163. Righi A, Asioli S, Caliendo V, et al. An ultrasonography-cytology protocol for the diagnostic management of regional nodes in a subset of patients with Merkel cell carcinoma of the skin. Br J Dermatol 2013;168:563-570.

164. Hoeller U, Mueller T, Schubert T, et al. Regional nodal relapse in surgically staged Merkel cell carcinoma. Strahlenther Onkol 2015;191:51-58.

165. Ko JS, Prieto VG, Elson PJ, et al. Histological pattern of Merkel cell carcinoma sentinel lymph node metastasis improves stratification of stage III patients. Mod Pathol 2016;29:122-130.

166. Meeuwissen JA, Bourne RG, Kearsley JH. The importance of postoperative radiation therapy in the treatment of Merkel cell carcinoma. Int J Radiat Oncol Biol Phys 1995;31:325-331.

167. Kokoska ER, Kokoska MS, Collins BT, et al. Early aggressive treatment for Merkel cell carcinoma improves outcome. Am J Surg 1997;174:688-693.

168. Eich HT, Eich D, Staar S, et al. Role of postoperative radiotherapy in the management of Merkel cell carcinoma. Am J Clin Oncol 2002;25:50-56.

169. Mojica P, Smith D, Ellenhorn JD. Adjuvant radiation therapy is associated with improved survival in Merkel cell carcinoma of the skin. J Clin Oncol 2007;25:1043-1047.

170. Jabbour J, Cumming R, Scolyer RA, et al. Merkel cell carcinoma: assessing the effect of wide local excision, lymph node dissection, and radiotherapy on recurrence and survival in early-stage disease--results from a review of 82 consecutive cases diagnosed between 1992 and 2004. Ann Surg Oncol 2007;14:1943-1952.

171. Poulsen M, Round C, Keller J, et al. Factors influencing relapse-free survival in Merkel cell carcinoma of the lower limb--a review of 60 cases. Int J Radiat Oncol Biol Phys 2010;76:393-397.

172. Chen MM, Roman SA, Sosa JA, Judson BL. The role of adjuvant therapy in the management of head and neck merkel cell carcinoma: an analysis of 4815 patients. JAMA Otolaryngol Head Neck Surg 2015;141:137-141.

173. Grotz TE, Joseph RW, Pockaj BA, et al. Negative sentinel lymph node biopsy in Merkel cell carcinoma is associated with a low risk of same-nodalbasin recurrences. Ann Surg Oncol 2015;22:4060-4066.

174. Hasan S, Liu L, Triplet J, et al. The role of postoperative radiation and chemoradiation in merkel cell carcinoma: a systematic review of the literature. Front Oncol 2013;3:276.

175. Boyle F, Pendlebury S, Bell D. Further insights into the natural history and management of primary cutaneous neuroendocrine (Merkel cell) carcinoma. Int J Radiat Oncol Biol Phys 1995;31:315-323.

176. Gillenwater AM, Hessel AC, Morrison WH, et al. Merkel cell carcinoma of the head and neck: effect of surgical excision and radiation on recurrence and survival. Arch Otolaryngol Head Neck Surg 2001;127:149-154.

177. Eng TY, Boersma MG, Fuller CD, et al. Treatment of merkel cell carcinoma. Am J Clin Oncol 2004;27:510-515.

178. Veness MJ, Perera L, McCourt J, et al. Merkel cell carcinoma: improved outcome with adjuvant radiotherapy. ANZ J Surg 2005;75:275-281.

179. Lewis KG, Weinstock MA, Weaver AL, Otley CC. Adjuvant local irradiation for Merkel cell carcinoma. Arch Dermatol 2006;142:693-700.
180. Ghadjar P, Kaanders JH, Poortmans P, et al. The essential role of radiotherapy in the treatment of Merkel cell carcinoma: a study from the Rare Cancer Network. Int J Radiat Oncol Biol Phys 2011;81:e583-591.

181. Balakrishnan V, Berry S, Stew B, Sizeland A. Benefits of combined modality treatment of Merkel cell carcinoma of the head and neck: single institution experience. J Laryngol Otol 2013;127:908-916.

182. Strom T, Carr M, Zager JS, et al. Radiation therapy is associated with improved outcomes in Merkel cell carcinoma. Ann Surg Oncol 2016;23:3572-3578.

183. Takagishi SR, Marx TE, Lewis C, et al. Postoperative radiation therapy is associated with a reduced risk of local recurrence among low risk Merkel cell carcinomas of the head and neck. Adv Radiat Oncol 2016;1:244-251.

184. Han AY, Patel PB, Anderson M, et al. Adjuvant radiation therapy improves patient survival in early-stage Merkel cell carcinoma: a 15-year single-institution study. Laryngoscope 2018

185. Jouary $\mathrm{T}$, Leyral C, Dreno $\mathrm{B}$, et al. Adjuvant prophylactic regional radiotherapy versus observation in stage I Merkel cell carcinoma: a multicentric prospective randomized study. Ann Oncol 2012;23:10741080 .

186. Strom T, Naghavi AO, Messina JL, et al. Improved local and regional control with radiotherapy for Merkel cell carcinoma of the head and neck. Head Neck 2017;39:48-55.

187. Desch L, Kunstfeld R. Merkel cell carcinoma: chemotherapy and emerging new therapeutic options. J Skin Cancer 2013;2013:327150.

188. Saini AT, Miles BA. Merkel cell carcinoma of the head and neck: pathogenesis, current and emerging treatment options. Onco Targets Ther 2015;8:2157-2167.

189. Allen PJ, Zhang ZF, Coit DG. Surgical management of Merkel cell carcinoma. Ann Surg 1999;229:97-105.

190. Poulsen MG, Rischin D, Porter I, et al. Does chemotherapy improve survival in high-risk stage I and II Merkel cell carcinoma of the skin? Int J Radiat Oncol Biol Phys 2006;64:114-119.

191. Arron ST, Canavan T, Yu SS. Organ transplant recipients with Merkel cell carcinoma have reduced progression-free, overall, and disease-specific survival independent of stage at presentation. J Am Acad Dermato 2014;71:684-690

192. Asioli S, Righi A, Volante M, et al. p63 expression as a new prognostic marker in Merkel cell carcinoma. Cancer 2007;110:640-647.

193. Fleming KE, Ly TY, Pasternak S, et al. Support for p63 expression as an adverse prognostic marker in Merkel cell carcinoma: report on a Canadian cohort. Hum Pathol 2014;45:952-960.

194. Frohm ML, Griffith KA, Harms KL, et al. Recurrence and survival in patients with Merkel cell carcinoma undergoing surgery without adjuvant radiation therapy to the primary site. JAMA Dermatol 2016;152:10011007.

195. Samimi M, Touze A, Laude H, et al. Vitamin D deficiency is associated with greater tumor size and poorer outcome in Merkel cell carcinoma patients. J Eur Acad Dermatol Venereol 2014;28:298-308.

196. Kervarrec T, Gaboriaud P, Berthon P, et al. Merkel cell carcinomas infiltrated with CD33(+) myeloid cells and CD8(+) T cells are associated with improved outcome. J Am Acad Dermatol 2018;78:973-982.

197. Johnson ME, Zhu F, Li T, et al. Absolute lymphocyte count: a potential prognostic factor for Merkel cell carcinoma. J Am Acad Dermatol 2014;70:1028-1035.

198. National Institutes of Health. Adjuvant therapy of completely resected Merkel cell carcinoma with immune checkpoint blocking antibodies versus observation (ADMEC-O). Available at: https://clinicaltrials.gov/ ct2/show/record/NCT02196961. Accessed May 3, 2018.

199. National Institutes of Health. Adjuvant Avelumab in Merkel Cell Cancer (ADAM). Available at: https://clinicaltrials.gov/ct2/show/record/ NCT03271372. Accessed May 3, 2018.

200. Sharma D, Flora G, Grunberg SM. Chemotherapy of metastatic Merkel cell carcinoma: case report and review of the literature. Am J Clin Oncol 1991;14:166-169.

201. Fenig E, Brenner B, Katz A, et al. The role of radiation therapy and chemotherapy in the treatment of Merkel cell carcinoma. Cancer 1997;80:881-885.

202. Tai PT, Yu E, Winquist E, et al. Chemotherapy in neuroendocrine/Merkel cell carcinoma of the skin: case series and review of 204 cases. J Clin Oncol 2000;18:2493-2499.

203. Iyer JG, Blom A, Doumani $R$, et al. Response rates and durability of chemotherapy among 62 patients with metastatic Merkel cell carcinoma. Cancer Med 2016;5:2294-2301. 
204. Cowey CL, Mahnke L, Espirito J, et al. Real-world treatment outcomes in patients with metastatic Merkel cell carcinoma treated with chemotherapy in the USA. Future Oncol 2017;13:1699-1710.

205. Becker JC, Lorenz E, Ugurel S, et al. Evaluation of real-world treatment outcomes in patients with distant metastatic Merkel cell carcinoma following second-line chemotherapy in Europe. Oncotarget 2017;8:7973179741.

206. Satpute SR, Ammakkanavar NR, Einhorn LH. Role of platinum-based chemotherapy for Merkel cell tumor in adjuvant and metastatic settings. J Clin Oncol 2014;32:9049-9049.

207. Mantripragada K, Birnbaum A. Response to anti-PD-1 therapy in metastatic Merkel cell carcinoma metastatic to the heart and pancreas. Cureus 2015;7:e403.

208. Patnaik A, Kang SP, Rasco D, et al. Phase I study of pembrolizumab (MK3475; anti-PD-1 monoclonal antibody) in patients with advanced solid tumors. Clin Cancer Res 2015;21:4286-4293.

209. Walocko FM, Scheier BY, Harms PW, et al. Metastatic Merkel cell carcinoma response to nivolumab. J Immunother Cancer 2016;4:79.

210. Winkler JK, Bender C, Kratochwil C, et al. PD-1 blockade: a therapeutic option for treatment of metastatic Merkel cell carcinoma. Br J Dermatol 2017;176:216-219.

211. Winkler JK, Dimitrakopoulou-Strauss A, Sachpekidis C, et al. Ipilimumab has efficacy in metastatic Merkel cell carcinoma: a case series of five patients. J Eur Acad Dermatol Venereol 2017.

212. Heppt MV, Schlaak M, Eigentler TK, et al. Checkpoint blockade for metastatic melanoma and Merkel cell carcinoma in HIV-positive patients. Ann Oncol 2017;28:3104-3106.

213. Kaufman HL, Russell J, Hamid O, et al. Avelumab in patients with chemotherapy-refractory metastatic Merkel cell carcinoma: a multicentre, single-group, open-label, phase 2 trial. Lancet Oncol 2016;17:1374-1385.

214. Kaufman HL, Russell JS, Hamid O, et al. Updated efficacy of avelumab in patients with previously treated metastatic Merkel cell carcinoma $\geq 1$ year of follow-up: JAVELIN Merkel 200, a phase 2 clinical trial. J Immunother Cancer 2018;6:7.

215. D'Angelo SP, Russell J, Lebbe C, et al. Efficacy and safety of first-line avelumab treatment in patients with stage IV metastatic Merkel cell carcinoma: a preplanned interim analysis of a clinical trial. JAMA Oncol 2018.

216. Nghiem PT, Bhatia S, Lipson EJ, et al. PD-1 Blockade with pembrolizumab in advanced Merkel-cell carcinoma. N Engl J Med 2016;374:2542-2552.

217. Topalian SL, Bhatia S, Hollebecque A, et al. Non-comparative, openlabel, multiple cohort, phase $1 / 2$ study to evaluate nivolumab (NIVO) in patients with virus-associated tumors (CheckMate 358): efficacy and safety in Merkel cell carcinoma (MCC) [abstract]. Presented at the American Association for Cance Research Annual Meeting; Washington, DC. Abstract CT074.

218. Prescribing information: BAVENCIO (avelumab) injection, for intravenous use 2017. Available at: https://www.accessdata.fda.gov/ drugsatfda_docs/label/2017/761049s002lbl.pdf. Accessed May 3, 2018.

219. National Institutes of Health. A Study of T-VEC (Talimogene Laherparepvec) With or Without Radiotherapy for Melanoma, Merkel Cell Carcinoma, or Other Solid Tumors. Available at: https://clinicaltrials. gov/ct2/show/record/NCT02819843. Accessed May 3, 2018.

220. National Institutes of Health. Talimogene Laherparepvec and Nivolumab in Treating Patients With Refractory Lymphomas or Advanced or Refractory Non-melanoma Skin Cancers. Available at: https://clinicaltrials.gov/ct2/ show/record/NCT02978625. Accessed May 3, 2018.

221. National Institutes of Health. Randomized Study of Nivolumab+Ipilimumab \pm SBRT for Metastatic Merkel Cell Carcinoma. Available at: https:// clinicaltrials.gov/ct2/show/record/NCT03071406. Accessed May 3, 2018.

222. National Institutes of Health. Pembrolizumab With or Without Stereotactic Body Radiation Therapy in Treating Patients With Advanced or Metastatic Merkel Cell Cancer. Available at: https://clinicaltrials.gov/ ct2/show/record/NCT03304639. Accessed May 3, 2018.

223. National Institutes of Health. T-VEC in Non-melanoma Skin Cancer (20139157 T-VEC). Available at: https://clinicaltrials.gov/ct2/show/ record/NCT03458117. Accessed May 3, 2018.

224. Prescribing information: KEYTRUDA (pembrolizumab) for injection, for intravenous use. 2017. Available at: https://www.accessdata.fda.gov/ drugsatfda_docs/label/2017/125514s0311bl.pdf. Accessed May 3, 2018.

225. Prescribing information: OPDIVO (nivolumab) injection, for intravenous use. 2018. Available at: https://www.accessdata.fda.gov/drugsatfda_docs/ label/2018/125554s058lbl.pdf. Accessed May 3, 2018.

226. Howard RA, Dores GM, Curtis RE, et al. Merkel cell carcinoma and multiple primary cancers. Cancer Epidemiol Biomarkers Prev 2006; 15:1545-1549.

227. Koljonen V, Kukko H, Tukiainen E, et al. Second cancers following the diagnosis of Merkel cell carcinoma: a nationwide cohort study. Cancer Epidemiol 2010;34:62-65.

228. Bzhalava D, Bray F, Storm H, Dillner J. Risk of second cancers after the diagnosis of Merkel cell carcinoma in Scandinavia. Br J Cancer 2011;104:178-180.

229. Youlden DR, Youl PH, Peter Soyer H, et al. Multiple primary cancers associated with Merkel cell carcinoma in Queensland, Australia, 1982-2011. J Invest Dermatol 2014;134:2883-2889. 
Merkel Cell Carcinoma, Version 1.2018

Individual Disclosures for Merkel Cell Carcinoma Panel

\begin{tabular}{|c|c|c|c|c|}
\hline Panel Member & $\begin{array}{l}\text { Clinical Research Support/Data } \\
\text { Safety Monitoring Board }\end{array}$ & $\begin{array}{l}\text { Scientific Advisory Boards, } \\
\text { Consultant, or Expert Witness }\end{array}$ & $\begin{array}{l}\text { Promotional Advisory Boards, } \\
\text { Consultant, or Speakers Bureau }\end{array}$ & $\begin{array}{l}\text { Date } \\
\text { Completed }\end{array}$ \\
\hline Sumaira Z. Aasi, MD & None & None & None & $5 / 5 / 18$ \\
\hline Murad Alam, MD, MBA, MSCI & None & None & None & $4 / 26 / 18$ \\
\hline James S. Andersen, MD & None & None & None & $3 / 21 / 17$ \\
\hline Christopher K. Bichakjian, MD & None & None & None & $3 / 2 / 18$ \\
\hline Rachel Blitzblau, MD, PhD & None & None & None & $5 / 2 / 18$ \\
\hline Glen M. Bowen, MD & Amgen Inc. & Castle Biosciences, Inc. & None & $5 / 2 / 18$ \\
\hline Carlo M. Contreras, MD & None & $\begin{array}{l}\text { Medical Review Institutes of } \\
\text { America; and Univadis }\end{array}$ & None & $5 / 3 / 18$ \\
\hline Gregory A. Daniels, MD, PhD & $\begin{array}{l}\text { Bristol-Myers Squibb Company; } \\
\text { Dynavax Technologies Corporation; } \\
\text { Eisai Inc.;mMerck \& Co., Inc.; Nektar } \\
\text { Therapeutics; Prometheus; Regeneron } \\
\text { Pharmaceuticals, Inc.; and Viralytics }\end{array}$ & None & None & $1 / 25 / 18$ \\
\hline Roy Decker, MD, PhD & Merck \& Co., Inc. & $\begin{array}{l}\text { AstraZeneca Pharmaceuticals LP; } \\
\text { Merck \& Co., Inc.; and Regeneron } \\
\text { Pharmaceuticals, Inc. }\end{array}$ & AstraZeneca Pharmaceuticals LP & $5 / 3 / 18$ \\
\hline Jeffrey M. Farma, MD & Delcath Systems, Inc. & None & None & $5 / 2 / 18$ \\
\hline Kris Fisher, MD & & & & Pending \\
\hline Brian Gastman, MD & AbbVie, Inc.; and Merck \& Co., Inc. & EMD Serono, Inc. & $\begin{array}{l}\text { Castle Biosciences, Inc.; Merck \& } \\
\text { Co., Inc.; and Quest Imaging }\end{array}$ & $4 / 12 / 18$ \\
\hline Karthik Ghosh, MD & None & American College of Physicians & None & $3 / 1 / 18$ \\
\hline Roy C. Grekin, MD & None & None & None & $5 / 7 / 18$ \\
\hline Kenneth Grossman, MD, PhD & None & $\begin{array}{l}\text { Bristol-Myers Squibb Company; } \\
\text { Castle Biosciences Inc.; and Roche } \\
\text { Laboratories, Inc. }\end{array}$ & Roche Laboratories, Inc. & $1 / 26 / 17$ \\
\hline Alan L. Ho, MD, PhD & $\begin{array}{l}\text { AstraZeneca Pharmaceuticals LP; } \\
\text { Bristol-Myers Squibb Company; } \\
\text { Celldex Therapeutics; Eisai Inc.; } \\
\text { Genentech, Inc.; Kura Oncology, } \\
\text { Inc.; Novartis Pharmaceuticals } \\
\text { Corporation; and Regeneron } \\
\text { Pharmaceuticals, Inc. }\end{array}$ & $\begin{array}{l}\text { Ayala Pharmaceuticals, Inc.; } \\
\text { Regeneron Pharmaceuticals, Inc.; } \\
\text { and sanofi-aventis U.S. LLC }\end{array}$ & $\begin{array}{l}\text { Oncology Consortium; and Roche } \\
\text { Colombia }\end{array}$ & $5 / 7 / 18$ \\
\hline Karl D. Lewis, MD & $\begin{array}{l}\text { Regeneron Pharmaceuticals, Inc.; and } \\
\text { Roche Laboratories, Inc. }\end{array}$ & $\begin{array}{l}\text { Genentech, Inc.; Regeneron } \\
\text { Pharmaceuticals, Inc.; and Sun } \\
\text { Pharma }\end{array}$ & None & $5 / 3 / 18$ \\
\hline Manisha Loss, MD & None & None & None & $5 / 4 / 18$ \\
\hline \multicolumn{5}{|l|}{ Daniel D. Lydiatt, DDS, MD } \\
\hline Jane Messina, MD & None & None & None & $5 / 1 / 18$ \\
\hline Kishwer S. Nehal, MD & None & None & None & $4 / 10 / 18$ \\
\hline Paul Nghiem, MD, PhD & None & $\begin{array}{l}\text { EMD Serono, Inc.; Merck \& Co., Inc.; } \\
\text { and Pfizer Inc. }\end{array}$ & None & $4 / 30 / 18$ \\
\hline Thomas Olencki, DO & $\begin{array}{l}\text { Bristol-Myers Squibb Company; } \\
\text { Genentech, Inc.; Pfizer Inc.; and } \\
\text { Tracon Pharmaceuticals }\end{array}$ & None & None & $7 / 12 / 17$ \\
\hline Igor Puzanov, MD, MSCl & None & Amgen Inc. & None & $4 / 26 / 18$ \\
\hline Chrysalyne D. Schmults, MD, MS & $\begin{array}{l}\text { Genentech, Inc.; and } \\
\text { Regeneron Pharmaceuticals, Inc. }\end{array}$ & $\begin{array}{l}\text { Castle Biosciences, Inc.; and } \\
\text { Regeneron Pharmaceuticals, Inc. }\end{array}$ & None & $5 / 8 / 18$ \\
\hline Ashok R. Shaha, MD & None & None & None & $4 / 26 / 18$ \\
\hline Valencia Thomas, MD & None & None & None & $3 / 16 / 18$ \\
\hline Yaohui G. Xu, MD, PhD & None & None & None & $2 / 26 / 18$ \\
\hline John A. Zic, MD & None & None & None & $4 / 12 / 18$ \\
\hline
\end{tabular}

The NCCN Guidelines Staff have no conflicts to disclose. 